\title{
Experimental and Numerical Investigations of Surge Extension on a Centrifugal Compressor with Vaned Diffuser Using Steam Injection
}

\author{
Chuang Gao, ${ }^{1}$ Weiguang Huang, ${ }^{1}$ Tianhua Zheng, ${ }^{2}$ Kang Yang, \\ Haosen Yang, ${ }^{2}$ and Yun $\mathrm{Cao}^{2}$ \\ ${ }^{1}$ Shanghai Advanced Research Institute, Chinese Academy of Sciences, Shanghai, China \\ ${ }^{2}$ Division of Aerodynamics, Department of R\&D, Helan Turbines, Co., Ltd., China \\ Correspondence should be addressed to Chuang Gao; gaoc@sari.ac.cn
}

Received 7 February 2017; Revised 6 April 2017; Accepted 13 April 2017; Published 29 May 2017

Academic Editor: Ryoichi Samuel Amano

Copyright (C) 2017 Chuang Gao et al. This is an open access article distributed under the Creative Commons Attribution License, which permits unrestricted use, distribution, and reproduction in any medium, provided the original work is properly cited.

This paper presents the first report on surge extension with steam injection through both experimental and numerical simulation. The experimental section covers the test facility, instrumentation, and prestall modes comparison with and without steam injection. It is found that surge extension is not in proportion to injected steam. There exists an upper bound above which deteriorates the margin. Injection of less than $1 \%$ of the designed mass flow can bring about over $10 \%$ margin improvement. Test results also indicated that steam injection not only damps out prestall waves, but also changes prestall modes and traveling direction. At $90 \%$ speed, injection changed the prestall mode from spike to modal, while at $80 \%$ speed line, it made the forward traveling wave become backward. Through numerical simulation, location and number of injectors, molecular weight, and temperature of injected gas are modified to explore their influences on surge margin. Similar to the test results, there exists an upper bound for the amount of steam injected. The flow field investigation indicates that this bound is caused by the early trigger of flow collapse due to the injected steam which is similar to the tip leakage flow spillage caused spike stall in axial compressors.

\section{Introduction}

Compressor flow instabilities may occur if the fluid flow decreases below a certain limit. Rotating stall and surge are such aerodynamic instabilities that occur in both axial and centrifugal compressors [1-24]. Surge, however, can result both in severe vibration and damage to compressor units and in reduced efficiency. Although many researches were published in the open literature on these two phenomena, the prediction and control of surge are still far away from the requirement of industrial application. In most cases, this can only be done case by case as it depends on the design.

For impellers with a vaned diffuser, most of the researches attribute rotating stall and surge to the increase of incidence angle at low flow rate; however, Spakovszky [2] pointed out that vaneless space just in front of the vaned diffuser is the root cause of rotating stall in the NASA CC3 compressor. Schleer et al. [3] measured the trajectories of tip clearance vortex at different flow rates and concluded that the tip clearance vortex caused the surge incipience. More recently, researchers from the von Karman Institute and University of Hannover [4] noticed the influences of volute on both performance and instability.

To control rotating stall and surge in a centrifugal compressor, various design features have been investigated: selfcirculation device [13], variable inlet guide vanes (VIGV), adjustable vaned diffuser vanes, ported shroud [15], grooved diffuser [16], air injection, or bleeding [8].

The analyses for the prestall, stall inception, and the generation of fully developed stall were to explore the interrelationship among them and were then applied in the design of prewarning and stall control systems. Experimental exploration of compressor prestall or stall inception usually involves several transducers for unsteady pressure recording distributed circumferentially in one or more axial locations. The pressure transducer settings for axial compressors were 


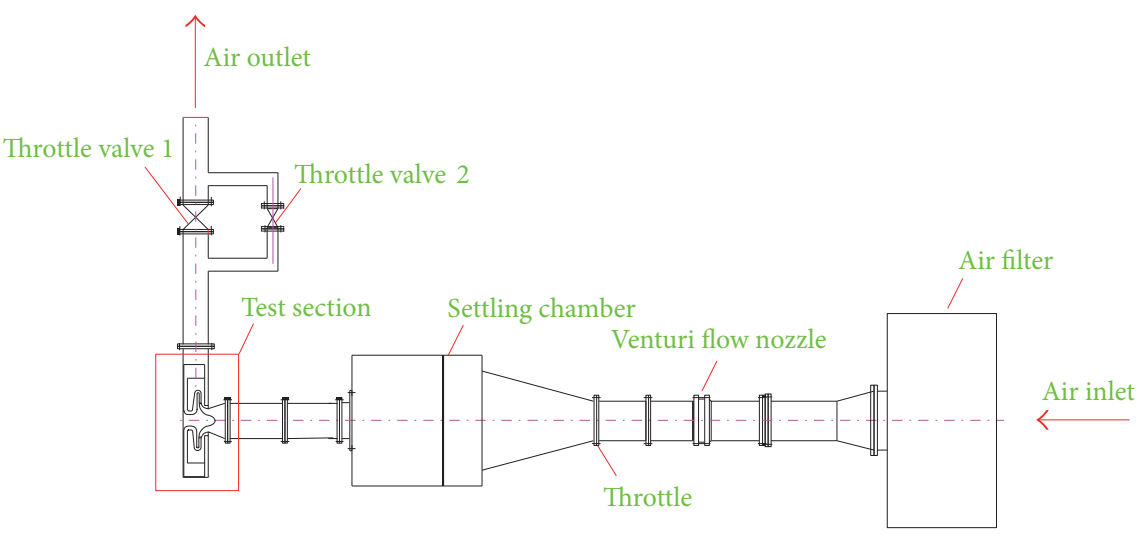

FIGURE 1: Schematic layout of the test facility.

often on the casing above the rotor [20] while the setup for centrifugal compressors sometimes may be considered on both the rotor and the diffuser to tell the stall inception location [24]. Pressure signals should be traced when compressors are throttled to stall. The definitions of prestall, stall inception, and fully developed stall (surge in some cases) were clearly described in [20] and can be understood according to the magnitude of pressure perturbation from relatively calm to large. Tryfonidis et al. [20] also indicated that the rotating stall influences the surge inception mechanism.

The stall wave was typically reported to travel in positive rotor direction as most of the axial compressor did, but in centrifugal compressors, negative traveling stall wave was also reported. Besides, two types of stall, modal stall and spike-like stall, were defined according to the stall length scale. With the theoretical background of this length scale study, various control methods were developed against different length scale stalls. Several methods have been conducted to analyze the circumferentially traveling pressure perturbation. Tryfonidis et al. [20] developed the spatial Fourier decomposition for stall inception area with the PSD analysis for traveling wave energy. In the past decades, the wavelet method was also quickly developed for further understanding of the physical mechanisms which lead to stall, but the result is sensitive to the parameter selection.

To sum up, researches on centrifugal compressor flow instabilities are still not enough for fully understanding and controlling rotating and surge.

Recently, with the stringent requirements on pollutant emissions, the Chinese government encourages distributed energy systems, especially combined cooling, heating, and power (CCHP) systems, in which the key component is a gas turbine. Considering the population of residential areas in most Chinese cities, it has been found that a gas turbine of $2 \mathrm{MW}$ output level is best suited for CCHP systems. At this power level, the gas turbine efficiency is much lower than those used in power plants. Generally, small gas turbines are always used together with a HRSG (heat recovery steam generator) which could provide heating in winter and cooling in summer with absorption refrigerating machine.

In most parts of China, however, there are almost no requirements on both cooling and heating in transitional seasons, which means that the gas turbine has to be shut down due to its low simple cycle efficiency.

With such background, the authors intend to boost the power output and efficiency through reinjecting the steam from the HRSG. However, to fulfill this aim, the compressor surge line has to be moved to the left due to the increased back pressure caused by the steam injected. Then, a question arises: can we use part of the power boost steam to increase the surge margin without using an external air supply?

The current paper reports related experimental results about impeller and vaned diffuser. The structure of the paper could be summarized as follows. A brief introduction is provided in Section 1. Test facility, experimental procedure, and data acquisition are illustrated in Section 2. The influences of steam injection characteristics at different rotational speeds on stage performance and surge range are discussed in Section 3. Prestall modes are analyzed and compared between a solid casing and one with steam injection in Section 5. Numerical models, compressor performance, surge margin, and diffuser inlet flow angle variation with steam mass flow are investigated using the same configuration as test facility. Flow physics for surge enhancement are then discussed in Section 6. Section 7 covers influences of injected gas properties, injector configuration, and so forth in detail. Conclusion and acknowledgment are given in the last two sections.

\section{Test Facilities and Instrumentation}

2.1. Test Facilities. The experiments were conducted on the $500 \mathrm{~kW}$ DC motor driven test rig at the Product Laboratory in Shaanxi Blower Company. Figure 1 shows the schematic layout of the test facility.

Ambient air is drawn into the pipe through an air filter and through a flow nozzle to measure the flow rate. The settling chamber is used to lower the gas velocity and make the impeller incoming flow more uniform. After the test section, the compressed air is discharged into the atmosphere. The mass flow rate can be adjusted by two valves. The cross section of the test section is shown in Figure 2.

The test impeller is scaled down by a factor of 0.5 to reduce the power consumption so that it can be driven by the motor 


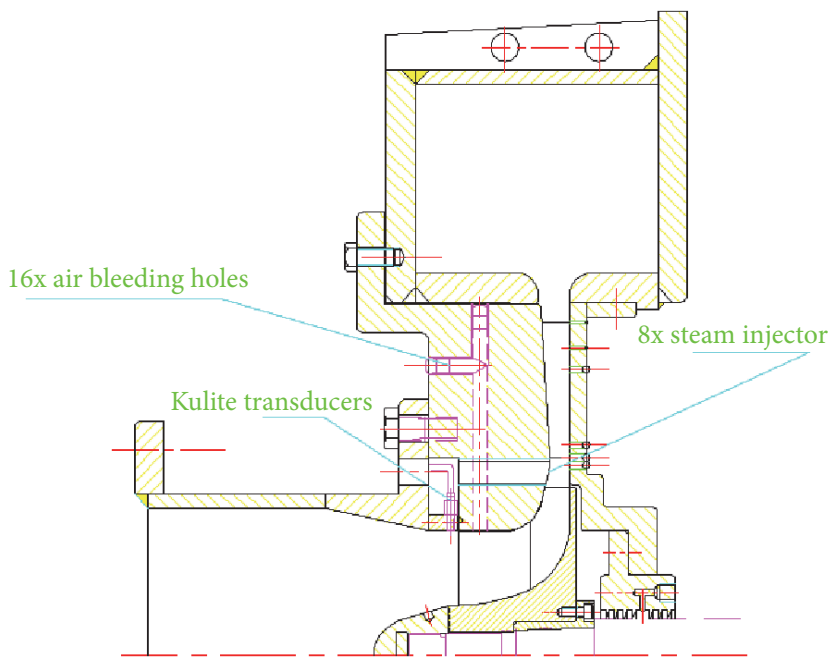

Figure 2: Cross-sectional view of the test section.

TABLE 1: Typical design parameters.

\begin{tabular}{lcc}
\hline Total pressure ratio & - & 3.55 \\
Designed mass flow rate & $\mathrm{kg} / \mathrm{s}$ & 3.2 \\
Impeller tip speed & $\mathrm{m} / \mathrm{s}$ & 433 \\
Blade number & - & $16+16$ \\
Impeller tip radius & $\mathrm{m}$ & 0.115 \\
Average blade exit angle & $\mathrm{Deg}$ & 90 \\
Impeller blade inlet angle & $\mathrm{Deg}$ & 52 \\
$n_{s}$ (dimensionless) & - & 0.83 \\
Diffuser inlet angle & Deg & 1.6 \\
Diffuser vane number & - & 23 \\
Diffuser area ratio & - & 2.1 \\
\hline
\end{tabular}

on site. For the scaled version, the primary design parameters are given in Table 1.

In the present test, the compressor was operated at $60 \%$, $70 \%, 80 \%$, and $90 \%$ of the design speed to reduce the risk of potential surge damage at $100 \%$ speed. Eight steam injectors were installed midway between the impeller tip and the diffuser leading edge. Sixteen air bleeding holes formed by radial channel and axial channel were used for impeller throat air bleeding, the results of which are not covered in the current paper.

The collector after the diffuser has a constant crosssectional area which is chosen to be 4 times the vaned diffuser outlet throat area to eliminate the asymmetric influences on upstream components.

2.2. Instrumentation. Compressor performance was evaluated by measuring the static pressure and temperature at the inlet of the impeller and the exit of the collector using a pressure transducer from Rosemount Engineering Co. A flow nozzle (shown in Figure 1) was used to measure the mass flow rate based on the pressure and temperature of the surroundings. A five-hole cobra probe with a thermocouple

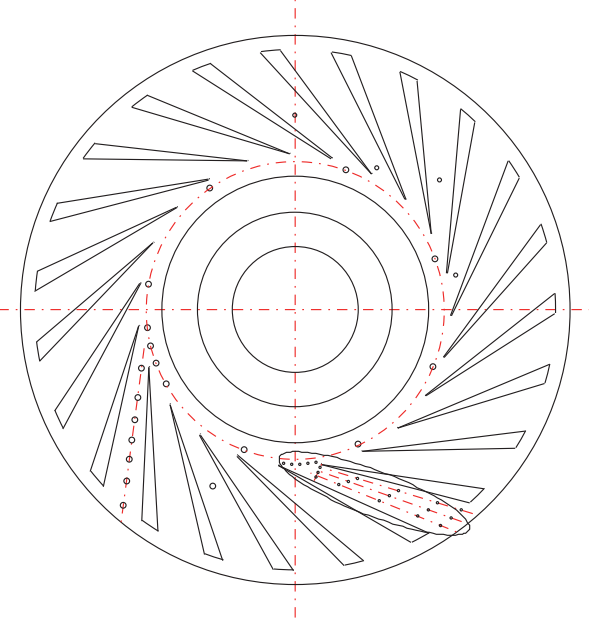

FIGURE 3: Steady and unsteady pressure taps in the diffuser.

was used to measure the total pressure and temperature at the impeller outlet $\left(r / r_{2}=1.04\right)$.

For the unsteady pressure measurements, 31 Kulite transducers were used. Six of them were uniformly installed $5 \mathrm{~mm}$ ahead of the impeller leading edge as shown in Figure 2. 23 of them were installed at the diffuser leading edge, in the diffuser throat, and inside the diffuser channel to record pressure data variation while throttling. The left two were installed in the exhaust collector. Besides the 23 unsteady transducers, 20 steady pressure taps circled by the ellipse shown in Figure 3 were in one channel to find pressure contour variation with reduction of flow rate.

The other two transducers are installed on the collector casing to study the flow behavior inside the collector. A photo of the test rig without shroud is shown in Figure 4 to show the location of the Kulite transducers in the diffuser.

During the test, two throttling valves were fully opened for steady operation at each speed line. Then, they are 


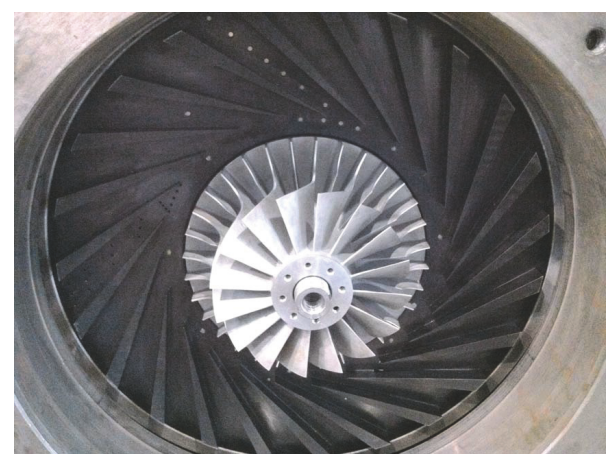

FIgURE 4: A photo of the test impeller and transducers.

gradually throttled until the compressor surges. For each speed line, at least six operating points are measured. At each point, all the unsteady pressure data were acquired and stored for at least 20 seconds. After all six performance data measurements are taken, two valves are opened a little to make the compressor operate at the nearest stable point; then, the valves are throttled gradually to push the compressor into surge; after several surge cycles, the valves are quickly opened to $100 \%$ in order to pull the compressor out of surge. Unsteady pressure data were acquired all through this process in order to analyze stall/surge precursor and pathology. Sampling frequency of all the 31 transducers was chosen to be $50 \mathrm{kHz}$ in order to avoid frequency alias and to provide enough time resolution.

\section{Effects of Steam Injection on Performance and Surge Extension}

Based on the analysis of component stability [24], accumulated shroud side separation due to centrifugal and Coriolis force, and positive results from Skoch [8], eight injectors are uniformly installed on the shroud side located in the middle of the impeller exit and diffuser leading edge to minimize impeller and diffuser mutual interaction. The position and tip segment of the injector are designed to take advantage of Coanda flow effects [18] as shown in Figure 5.

For the compressor test alone facility, the injected steam is generated from an electric boiler. The maximum steam mass flow rate is $200 \mathrm{~kg} / \mathrm{h}$. In the current experiment, the steam pressure is kept as 6 bar limited by the used electrical boiler and this number should be higher with HRSG used on site.

At constant impeller rotational speed, the injected steam mass flow is increased and kept at several different flow rates to investigate its influences on surge margin. At each steam flow rate, valves are gradually throttled to find the surge flow rate. In this paper, surge margin improvement (SMI) is defined as $\left(m_{s o}-m_{s}\right) / m_{s o} \times 100 \%$, in which $m_{s}$ and $m_{s o}$ are surge flow rates with and without steam injection, respectively.

Variations of SMI under $80 \%$ and $90 \%$ of the designed rotational speed for six different steam flow rates (I: $0.521 \mathrm{~g} / \mathrm{s}$, II: $1.042 \mathrm{~g} / \mathrm{s}$, III: $2.083 \mathrm{~g} / \mathrm{s}, \mathrm{IV}: 3.125 \mathrm{~g} / \mathrm{s}, \mathrm{V}: 4.167 \mathrm{~g} / \mathrm{s}$, and VI: $5.208 \mathrm{~g} / \mathrm{s}$ ) are shown in Figure 6.

In Figure 6, it is obviously observed that the trends for these two different rotational speeds are different especially at high steam flow rate. For the line with $\mathrm{Mu}=0.96$, there is an optimum steam flow for which the surge extension is maximized. This trend is kept the same for $\mathrm{Mu}=1.08$ except for the first point. For this point only, $0.15 \%$ designed mass flow rate can increase surge margin by over $11 \%$. This effect is the same as the fifth point of which the mass flow rate is seven times as large as that of the first point. The strange phenomenon is that the surge margin extension decreased with increasing injected steam mass flow rate. This implies that the traditional explanation based on flow angle might not be correct for the surge inception of centrifugal compressor or at least for this compressor. Detailed explanation was given in Section 4 from the point of different stall mode about the different trends shown by $80 \%$ and $90 \%$ speed line.

After reviewing the test data, it is found that steam injection brings about loss to both pressure ratio and efficiency as shown in Figure 7. Stage efficiency is defined by the following equation:

$$
\eta_{\text {stage }}=\frac{T_{t 1}\left[\left(P_{3, \mathrm{st}} / P_{t 1}\right)^{(n-1) / n}-1\right] m_{1}+T_{t 1, \text { inject }}\left[\left(P_{3, \mathrm{st}} / P_{t 1, \text { hole }}\right)^{(n-1) / n}-1\right] m_{\text {inject }}}{m_{1}\left(T_{3, \mathrm{st}}-T_{t 1}\right)+m_{\text {inject }}\left(T_{3, \mathrm{st}}-T_{t 1, \text { hole }}\right)} .
$$

Even with the same steam flow rate, the loss deviates greatly. For example, for the index equal to 5 (flow rate: $4.167 \mathrm{~g} / \mathrm{s}$ ), the loss at $\mathrm{Mu}=0.96$ is almost 8 times that of $\mathrm{Mu}=1.08$. Another interesting phenomenon is that good SMI points always coincide with good loss ones. The above phenomena shown by Figures 6 and 7 are repeatable at different ambient conditions from three test days.

\section{Prestall Modes and Surge Characteristics}

4.1. Unsteady Pressure Traces. Pressure traces at $80 \%$ and $90 \%$ with and without steam injection located at different streamwise locations (impeller inlet, semivaneless diffuser, diffuser throat, and diffuser midpassage) during stall ramp just before surge are presented in Figures 8(a)-8(d).

In Figure 8, it is observed that the prestall waves are pronounced at the diffuser throat which means that the dominant modes here are the diffuser modes. Thus, the following studies are focused on diffusers. The magnitude of pressure perturbations with injection is on the same level as the case without injection. Additionally, one interesting finding is that the prestall mode even changed from spike to be of modal type as shown in Figure 8(b) on 90\% rotational speed with the existence of steam. It can be explained that 


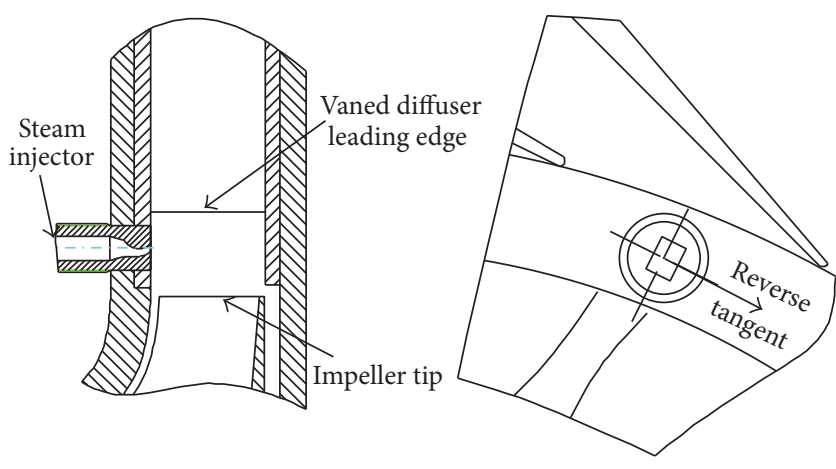

Figure 5: Steam injector.

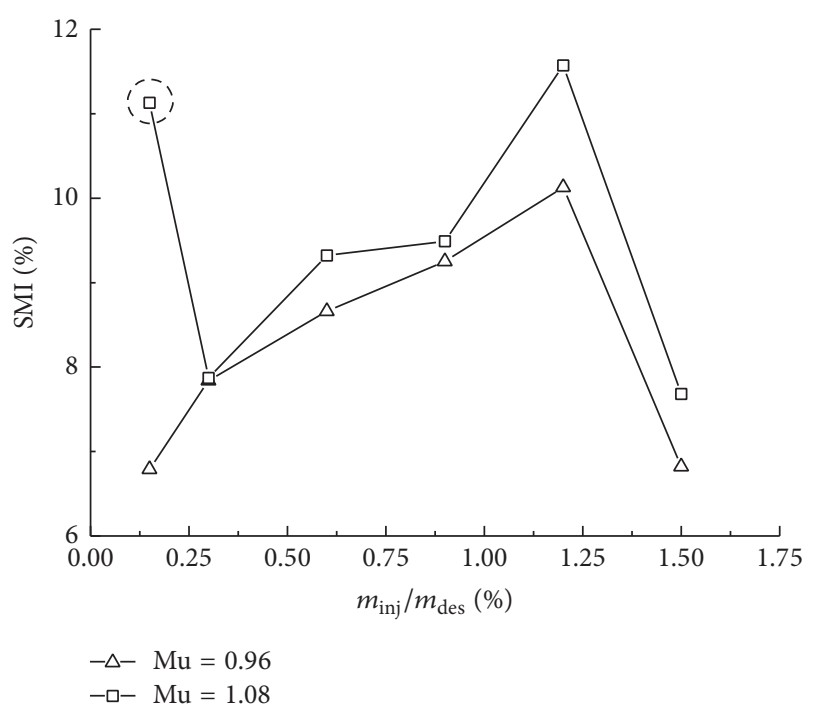

Figure 6: Steam injection percentages on surge extension.

the injected flow at shroud increases system damping which caused the prestall mode's variation from short wave (spike) to long wave (modal). Instead of flow injection in the current paper, endwall flow bleeding on the hub side can also generate similar effects as shown by Spakovszky and Roduner [5] in a turbocharger compressor.

With a closer view, it can also be seen that the steam injection damped out the pressure oscillation after surge (time $=0$ ) occurred through comparison of the wave segment in the black circle with the same segment with injection. It is worth noting that, after surge, the pressure traces at the impeller inlet behave much less violently than those in other locations or in the same location with steam injection on. This also indicates that surge root comes from the diffuser area. Damping that pressure perturbation amplitude can reduce the surge intensity.

This can also explain the strange phenomenon shown by Figure 6 in which the largest surge margin improvement is at the smallest injection flow at $90 \%$ speed line while the surge margin improvement at $80 \%$ speed line is gradually increased with the amount of steam flow. This means that, at $90 \%$ speed line, the prestall wave is a spike which is nonlinear. With the increase of steam injection, the prestall wave changes from spike to be modal which is linear long wave. And at $80 \%$ speed line, the prestall wave is always linear modal wave.

4.2. Traveling Wave Energy Analysis of Prestall Behavior. Traveling wave energy method was used to analyze the prestall wave traveling frequency and direction. The $x$ - and $y$ axis of the TWE spectra depicted in Figure 9 were normalized by rotor revolution and rotor frequency $(\mathrm{N}$ means one rotor 1x frequency in later description), respectively. To further analyze this prestall activity, the pressure signals are decomposed into spatial Fourier harmonics. For each harmonic, the evolution of power spectrum is then computed. The plotted spectrum is the difference between the positive and the negative frequency spectra of the complex spatial Fourier coefficient. Peaks and valleys therefore stand for the forward (with the rotor revolution direction) and backward (against the rotor revolution direction) traveling waves as described by Tryfonidis et al. [20]. In Figures 9 and 10, the time index equal to zero is assigned for fully developed stall (surge).

Figure 9 shows the 90\% TWE results without steam injection. The impeller rotating frequency which is $1 \mathrm{~N}$ was clearly shown. The $0.3 \mathrm{~N}$ frequency was the first stall frequency emerging at relatively high mass flow rate compared with that of surge point, and $0.13 \mathrm{~N}$ that appeared in the $3 \mathrm{rd}$ harmonic just before surge is the second stall frequency. The $0.3 \mathrm{~N}$ frequency in the 1st harmonic is clearly the dominant frequency and mode before surge, and $0.13 \mathrm{~N}$ frequency is the dominated stall precursor in the 3rd mode. Both stall precursors traveled in the forward direction.

However, with $120 \mathrm{~kg} / \mathrm{h}$ steam injection, the $0.3 \mathrm{~N}$ frequency was suppressed and almost invisible. The $0.13 \mathrm{~N}$ frequency dominated all the other harmonics as shown in Figures 10 and 11. In Figure 11, due to the in-phase or unchanged phase features of the 4 pressure traces at different circumferential angles, the authors claim that these circumferential areas are covered by one stall cell. This means that, after steam injection, there exists one big stall cell that moves in the impeller rotation direction in the speed ratio of $13 \%$.

For the $80 \%$ TWE results with/without steam injection, the results are similar. The $0.22 \mathrm{~N}$ frequency was the first stall wave emerging at relatively high mass flow rate and the $0.13 \mathrm{~N}$ appeared in the 2nd harmonic just before surge. The only difference and strange thing is that the prestall modal wave traveling direction of $0.13 \mathrm{~N}$ shifts from forward (rotation direction) to be backward (against rotation direction). This phenomenon can be observed by listing all circumferential unsteady pressure traces in circumferential direction as shown in Figure 12. This further complicates surge scenario and was also never been reported before in public references. Similarly, as shown in Figure 11, Figure 12 also indicates a stall cell moving slowly against impeller rotation direction with injected steam but with larger size than the case of $90 \%$.

Detailed influences of the amount of steam injection $(0 \mathrm{~kg} / \mathrm{h}, 30 \mathrm{~kg} / \mathrm{h}, 60 \mathrm{~kg} / \mathrm{h}$, and $120 \mathrm{~kg} / \mathrm{h})$ on prestall mode activity at two different rotational speeds ( $80 \%$ and $90 \%)$ in a semivaneless space are summarized in Figure 13. At $80 \%$ speed, the $0.22 \mathrm{~N}$ content only existed at $0 \mathrm{~kg} / \mathrm{h}$ and was suppressed in other cases. With the increase of injection flow, 


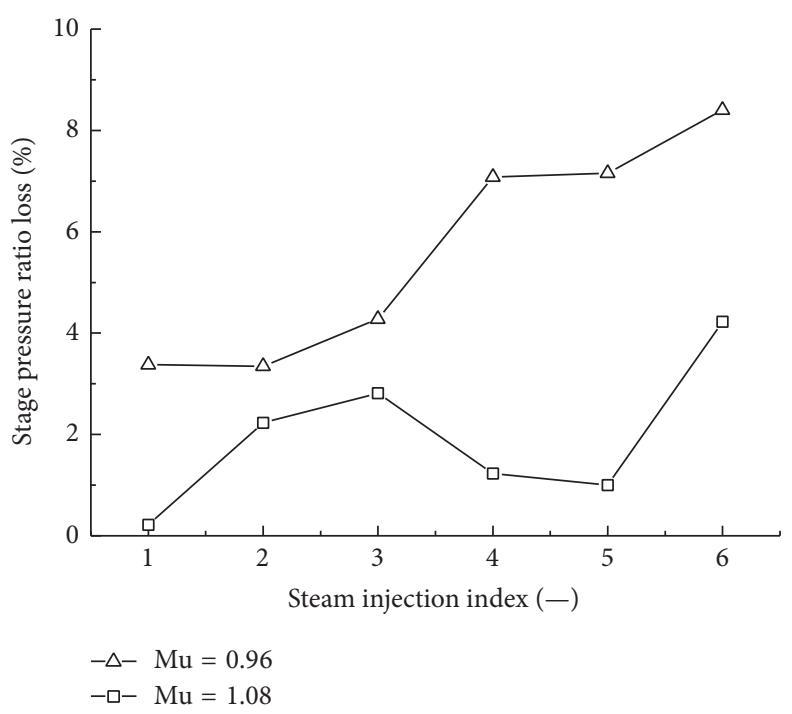

(a) Stage pressure loss versus steam injection index

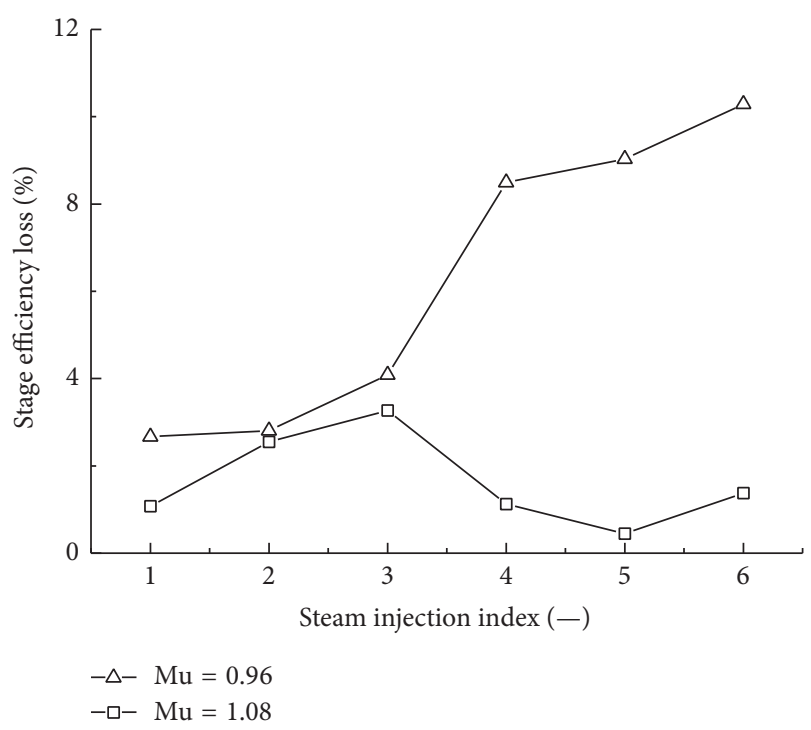

(b) Stage efficiency loss versus steam injection index

FiguRe 7

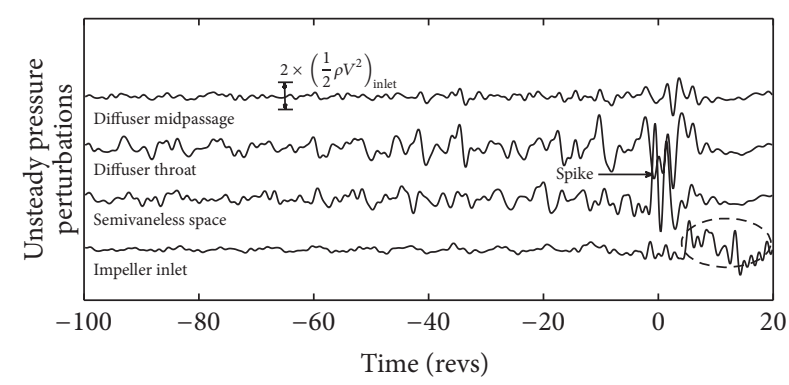

(a) $90 \%$ speed without steam injection

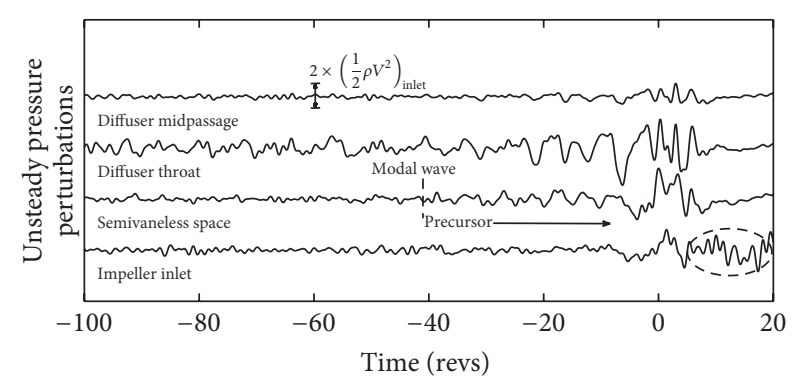

(c) $80 \%$ speed without steam injection

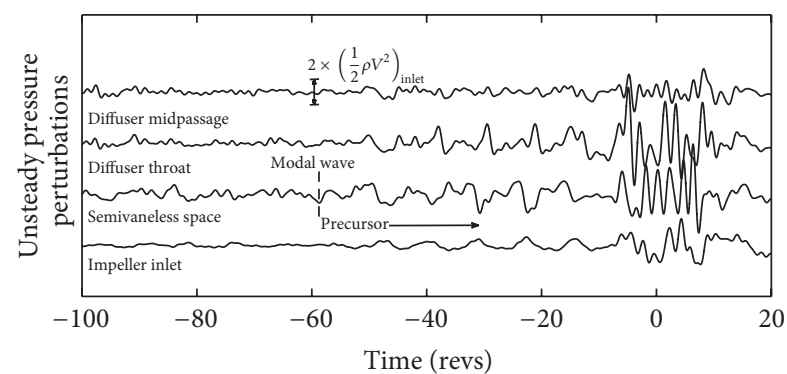

(b) $90 \%$ speed with $120 \mathrm{~kg} / \mathrm{h}$ steam injection

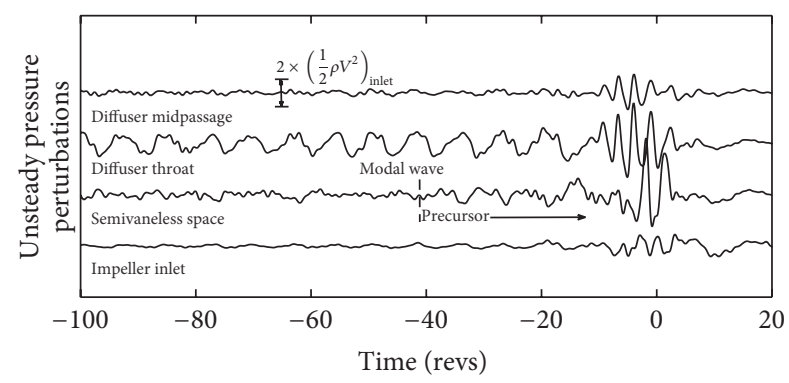

(d) $80 \%$ speed with $60 \mathrm{~kg} / \mathrm{h}$ steam injection

FIGURE 8: Pressure perturbation analysis for streamwise locations.

the amplitude of prestall waves was gradually attenuated. At $90 \%$ speed, the frequency of the original $0.3 \mathrm{~N}$ prestall wave decreased from $0.3 \mathrm{~N}$ to be $0.23 \mathrm{~N}$ with $120 \mathrm{~kg} / \mathrm{h}$. With $150 \mathrm{~kg} / \mathrm{h}$ injection flow (not shown in the figure), this content is completely suppressed. From the figure, nonlinear coupling between different modes can be easily found which means one mode always has contributions from other harmonics by seeing that the same frequency exists in different modes. It can be observed that $30 \mathrm{~kg} / \mathrm{h}$ injection damps out almost all the prestall modes compared to other amounts of injections. If, further, more steam is injected, some higher modes can be damped further, but not that obviously. These observations agree well with test results shown in Figure 6.

4.3. Discussion on Experimental Results. Depending upon steam quality (superheated/saturated), nozzle parameter (position/number/angle), and other factors, there are several things that happen with steam injection into the flow path. These things are as follows:

(a) The injection of steam into the flow path has an effect on the properties of the flow, especially in changes 

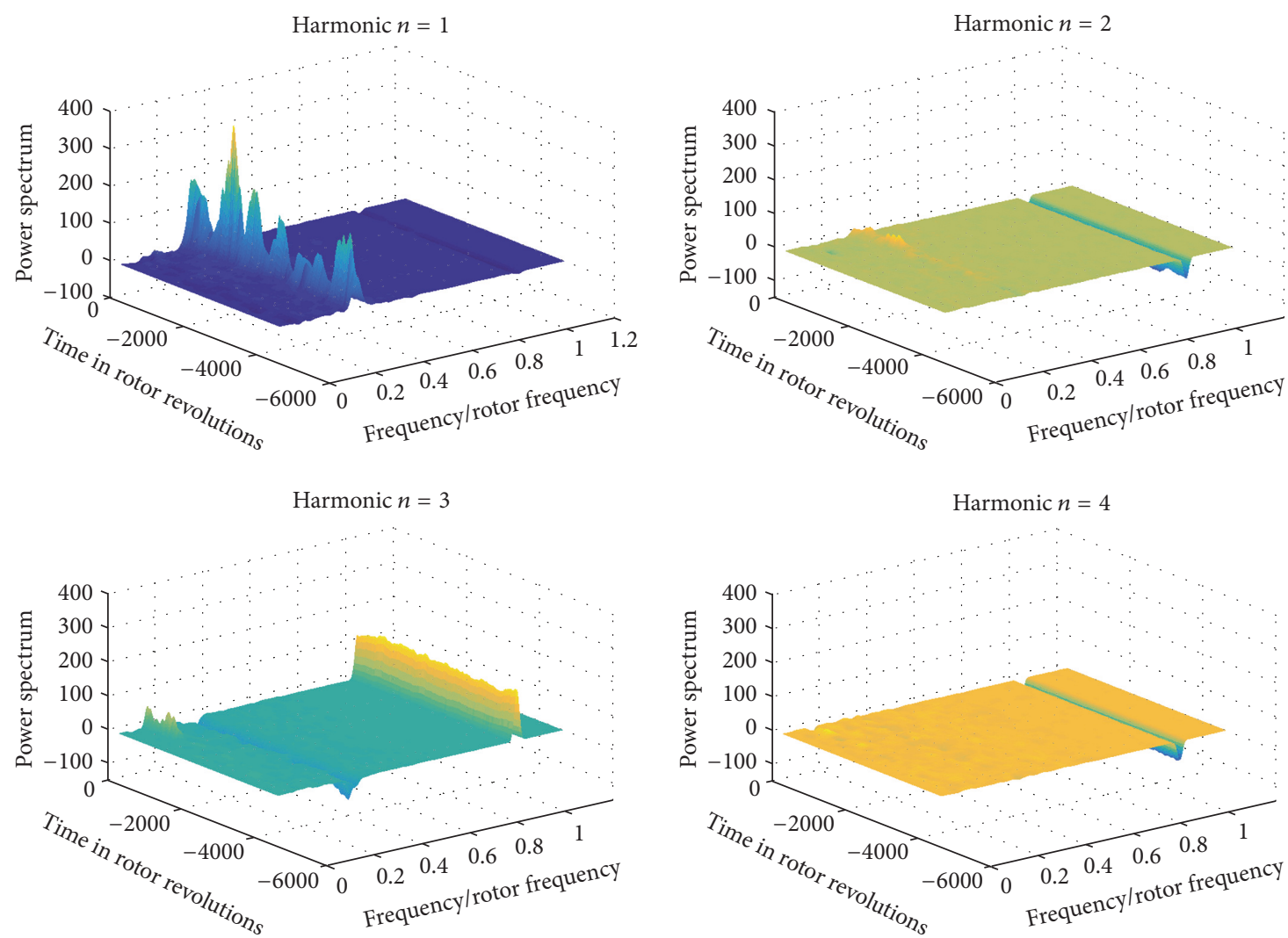

FIGURE 9: Spectrograms of the 1st, 2nd, 3rd, and 4th spatial harmonic pressure perturbations during stall ramp at $90 \%$ design speed without steam injection.

to the gas constant, theta, and gamma. This finally changes the operating characteristics of the diffuser.

(b) Depending upon temperature difference between steam and air, the heat transfer effect between the two fluids influences the incidence angle of the diffuser through changes in velocity vectors.

(c) The different nonuniform temperature in both circumferential and axial directions changes the local corrected speed and local corrected flow which makes different parts of the diffuser work under different inlet flow conditions.

(d) The steam injection can enhance the flow momentum of the flow near the shroud where wake and separation always exist and delay the flow separation which improves diffuser stability.

(e) At subsonic diffuser inlet conditions, steam injection can also have certain influences on the impeller performance which might also be beneficial for the stability.

To answer the above questions, numerical simulations and detailed flow field analysis were performed.

\section{Numerical Procedures}

Full annulus numerical grids are meshed with impeller, injector, vaned diffuser, and volute. The grids are blade centered
TABLE 2: Mesh densities of CFD domains.

\begin{tabular}{lc}
\hline Domain & Numbers of grids \\
\hline Rotor & 2328384 \\
Diffuser & 2435424 \\
Injector & 180168 \\
Collector & 289856 \\
\hline Total & 5233832 \\
\hline
\end{tabular}

multiblocks with hexahedral structure. The stator and rotor grids had ATM optimized topology which was a proprietary blocking strategy for obtaining good quality grids. The grids were made finer at the regions where high gradients were expected in the flow passage. The 3D computational grids used in the analysis are shown in Figure 14. The mesh in the boundary layers was refined to ensure $\mathrm{Y}+$ ranged from 30 to 40, the total grids number was about 5.2 million, and mesh densities after grid independency check for each component are given in Table 2 .

The $k$ - $\epsilon$ turbulence model with a scalable wall function was chosen. A total pressure and total temperature inlet boundary condition were used at the rotor inlet, a mass flow outlet boundary condition was set at the diffuser outlet, and a second mass flow inlet was defined at the injectors inlet. The rotor domain was solved in rotational coordinate frame with rotational speed of $30780 \mathrm{rpm}$. The rotor domain and 

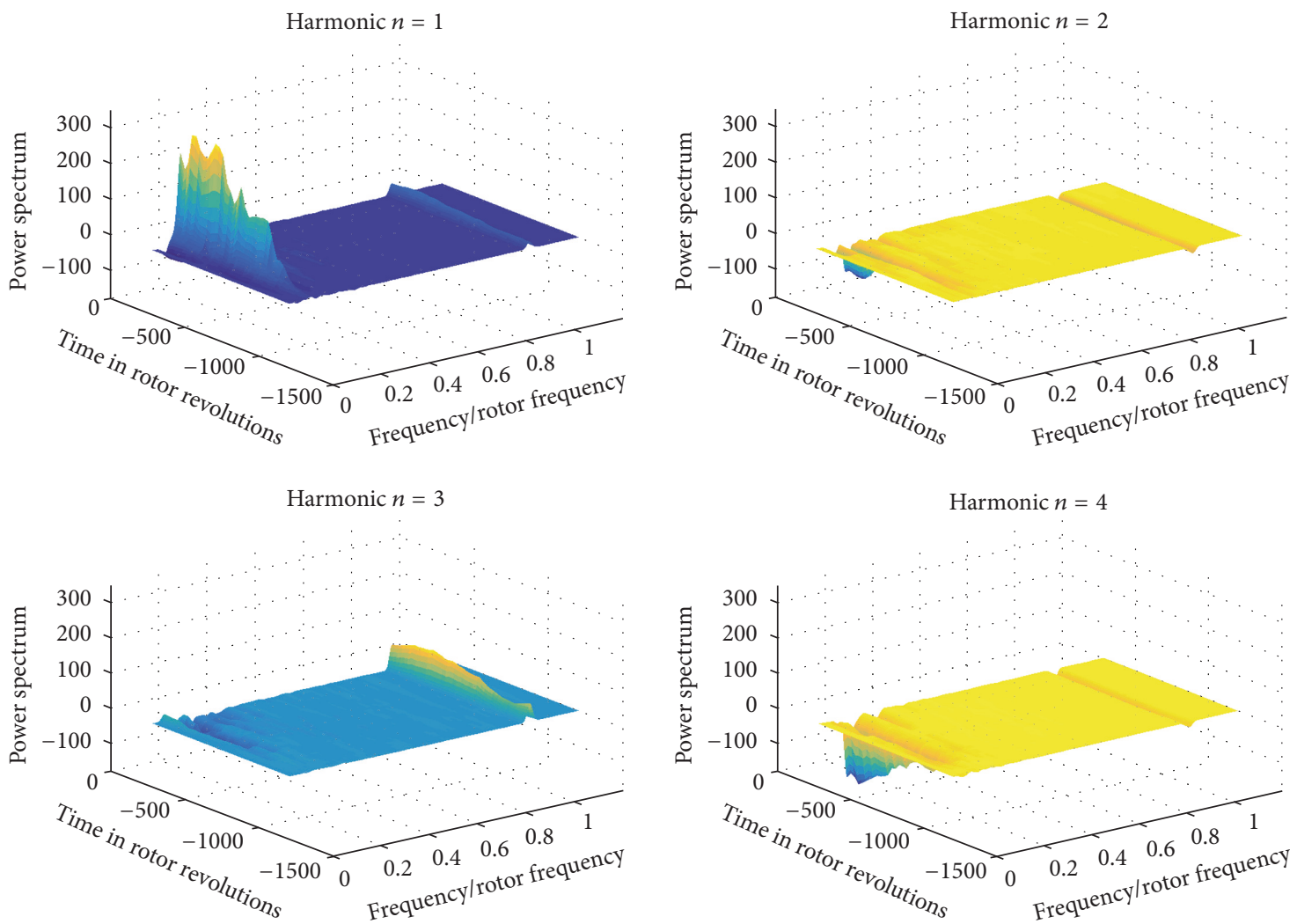

FIGURE 10: Spectrograms of the 1st, 2nd, 3rd, and 4th spatial harmonic pressure perturbations during stall ramp at $90 \%$ design speed with $120 \mathrm{~kg} / \mathrm{h}$ steam injection.

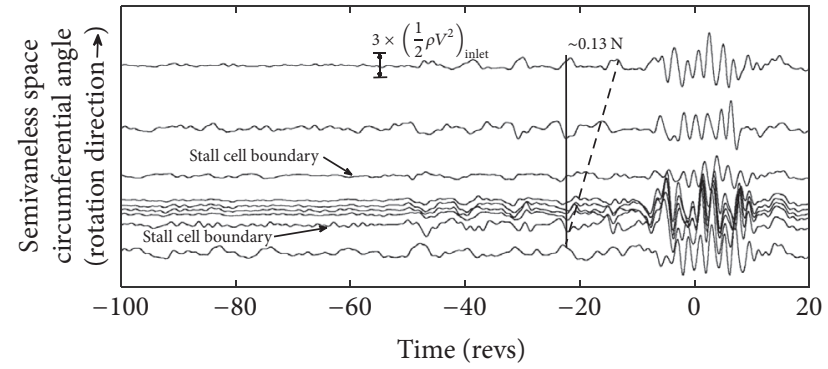

FIGURE 11: Unsteady pressure traces at $90 \%$ speed with $120 \mathrm{~kg} / \mathrm{h}$ steam injection (Kulite transducers all located in a semivaneless space).

injection domain exchanged boundary conditions across the mixing plane interface. The downstream side was treated as an inlet face with the boundary conditions defined by averaged flow properties at the impeller exit. The upstream impeller side could be seen as an outlet face with the exit flow condition being provided by the diffuser inlet flow. The case was considered to be converged when the RMS was below $1 e-5$ and the variation of the TTE (total-to-total efficiency) was within $3 \%$.

Compressor performance was evaluated by measuring the static pressure and temperature at the inlet of the impeller and exit of the gas collector using a pressure transducer from Rosemount Engineering Co., Ltd. A flow nozzle was used

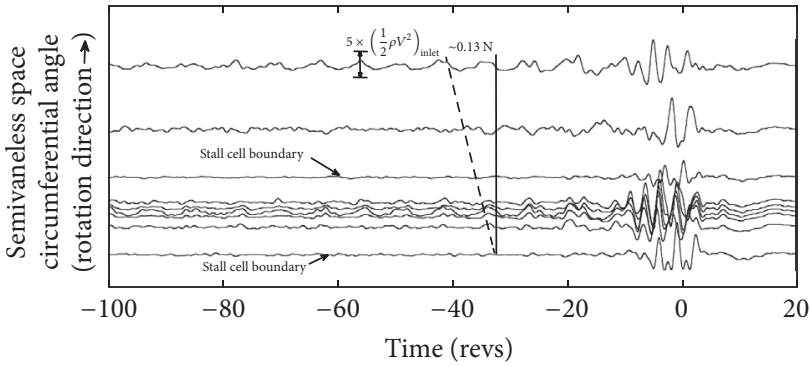

FIGURE 12: Unsteady pressure traces at $80 \%$ speed with $60 \mathrm{~kg} / \mathrm{h}$ steam injection (Kulite transducers all located in a semivaneless space).

to measure the mass flow rate based on the pressure and temperature of the surroundings. A five-hole cobra probe with a thermoresistor was used to measure the total pressure and temperature just at the impeller outlet.

Figure 15 presents the comparisons between computed and measured compressor characteristics with $120 \mathrm{~kg} / \mathrm{h}$ steam injection and without steam injection at $90 \%$ speed, which plotted both the TTPR and the TTE as a function of diffuser exit mass flow corrected to sea level total pressure and temperature; the choke limit and the surge limit frame the operating range on both ends of the abscissa. Both the CFD predictions and the experimental datum with steam injection extended the stable flow range, while around 5\% drops in 

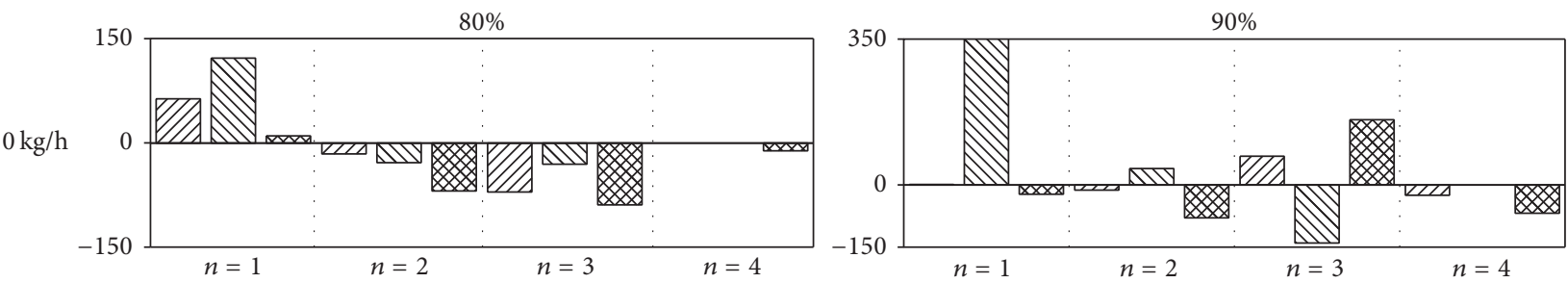

ए7A $0.13 \mathrm{~N}$

DIV $0.22 \mathrm{~N}$

$1 \mathrm{~N}$

EIA $0.13 \mathrm{~N}$

$0.3 \mathrm{~N}$

1 N
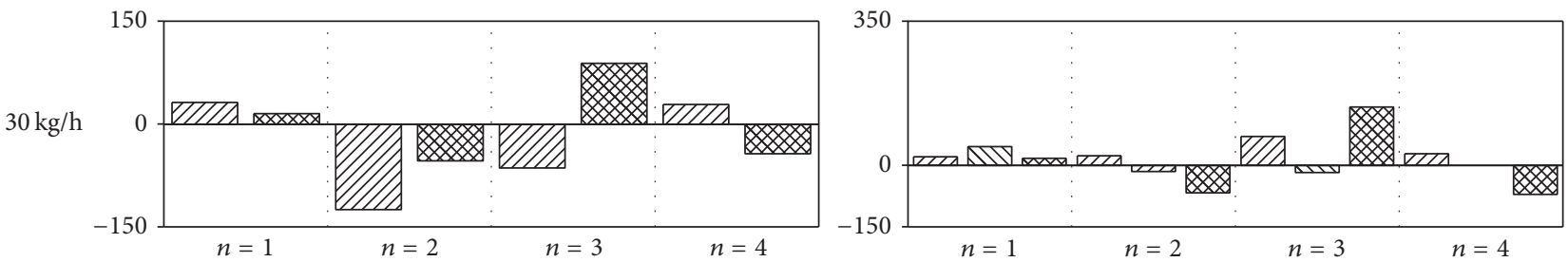

IIA $0.13 \mathrm{~N}$

DIV $0.22 \mathrm{~N}$

$1 \mathrm{~N}$

EAS $0.13 \mathrm{~N}$

DIV $0.3 \mathrm{~N}$

$1 \mathrm{~N}$
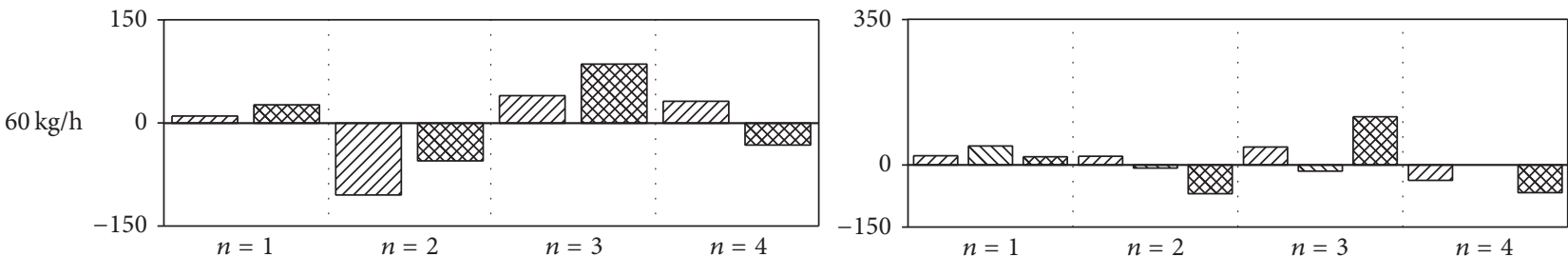

IIA $0.13 \mathrm{~N}$

$0.22 \mathrm{~N}$

$1 \mathrm{~N}$

ED $0.13 \mathrm{~N}$

DIV $0.27 \mathrm{~N}$

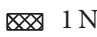
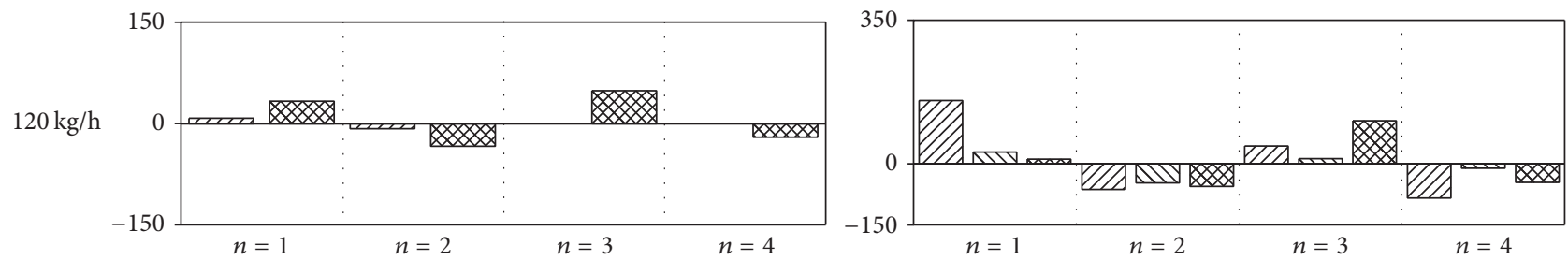

एב $0.13 \mathrm{~N}$

EDA $0.13 \mathrm{~N}$

NIV $0.23 \mathrm{~N}$

$\otimes 1 \mathrm{~N}$

$1 \mathrm{~N}$

FIGURE 13: Harmonic content of traveling energy of the first four prestall modes at the diffuser inlet.

pressure ratio and efficiency were observed in steam injected technology compressors.

The overall agreement between experiments and computational data was reasonable. The simulation characteristics indicated a higher pressure rise and higher efficiency than that observed in experiment. The difference in pressure ratio and efficiency between the measurements and CFD calculations could possibly be attributed to the turbulence model. As the full flow passage model cases were simulated, $\kappa-\epsilon$ turbulence model was selected in order to procure convergence in the calculations. However, some loss may be ignored and the compressor performance was improved.

\section{Mechanisms of Surge Enhancement with Steam Injection}

In order to clearly identify the effect of steam injection on impeller and vaned diffuser, the individual components of the stage were studied separately. Impeller total efficiency and pressure recovery coefficient $(\mathrm{Cp})$ of the vaned diffuser based on the CFD results are used to depict the performance of the impeller and the diffuser. Calculated results with different steam flow rates at the same operating point are shown in Figure 16. Each curve is composed of 20 different span stations from hub to shroud, that is, from 0.0 to 1.0. Thus, the 


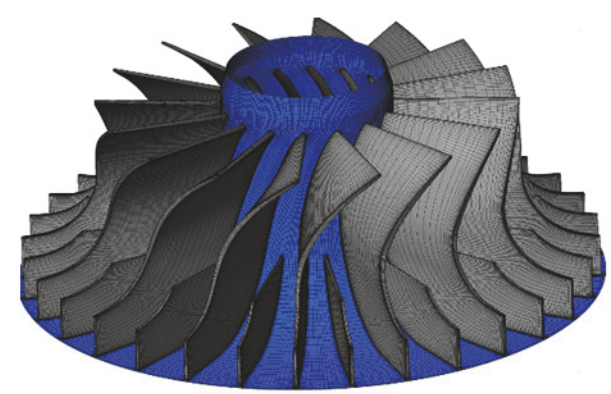

(a) Rotor mesh details

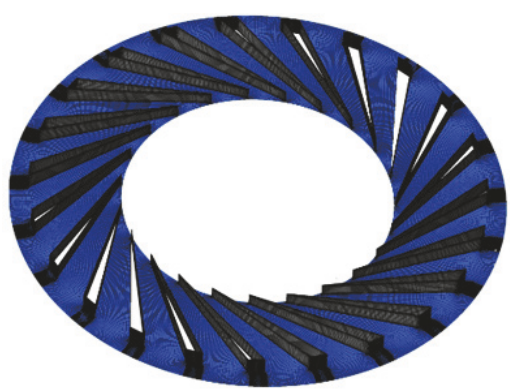

(b) Stator mesh details

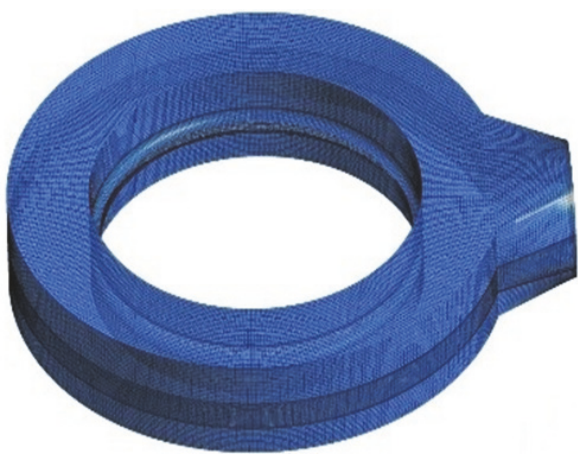

(d) Volute mesh details

FIGURE 14: CFD computational grids.

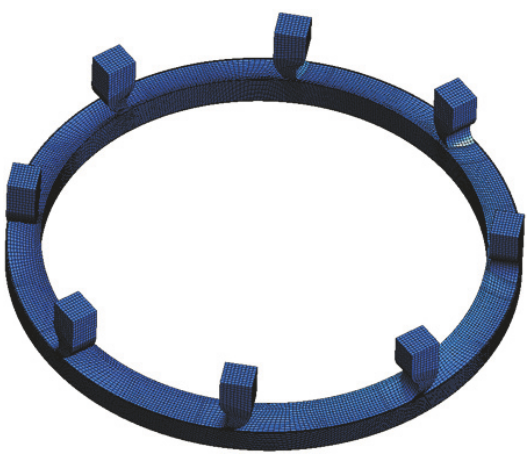

(c) Injection mesh details
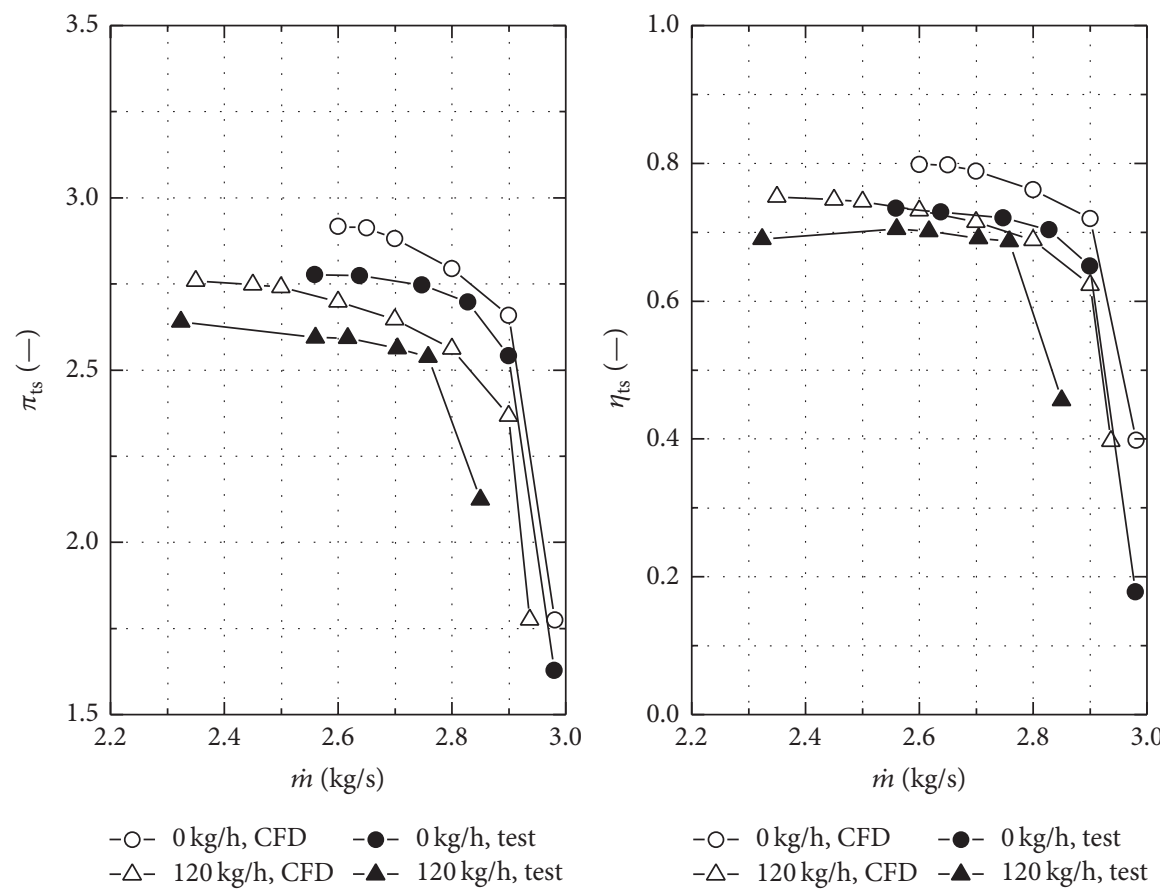

FIGURE 15: Performance comparison between numerical simulation and test results. 

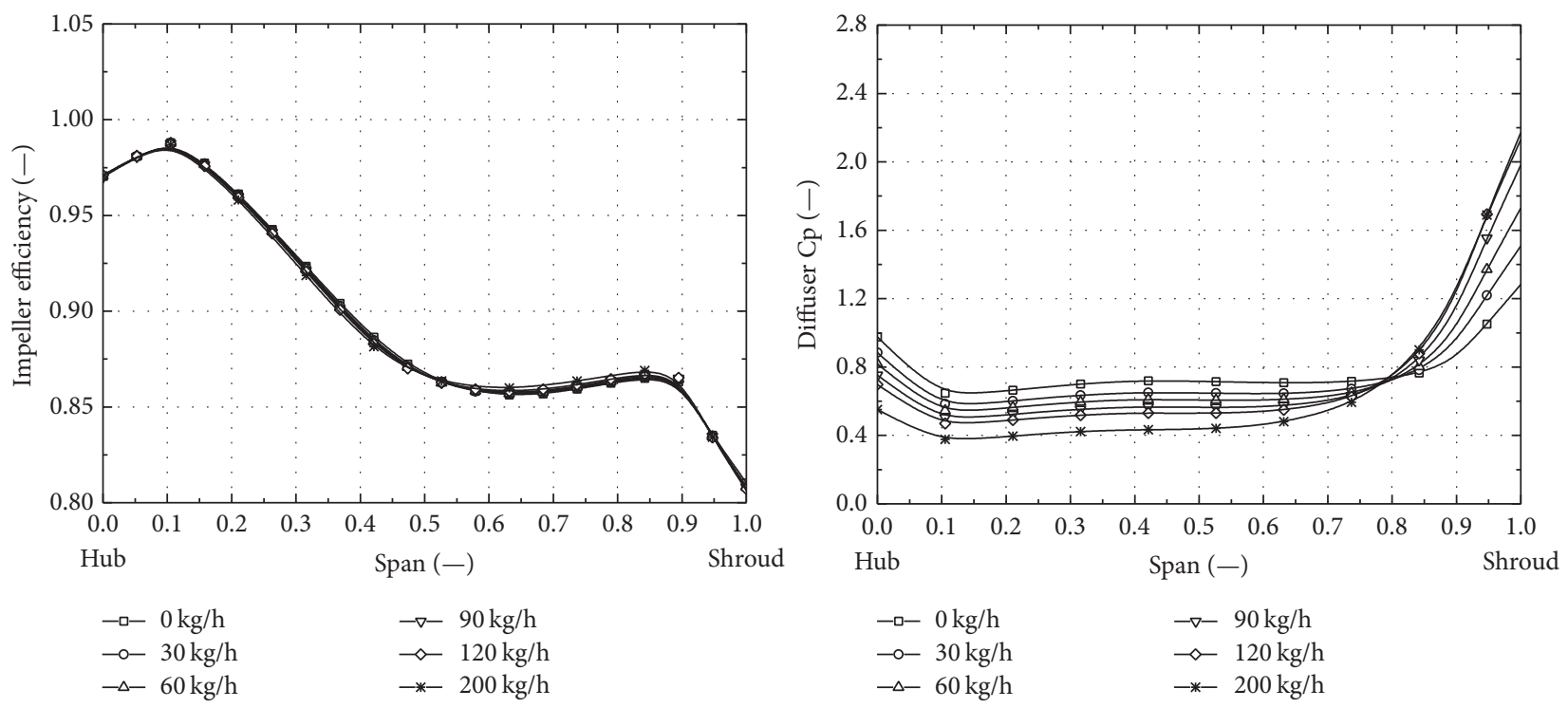

FIGURE 16: Characteristics of the impeller and the diffuser.

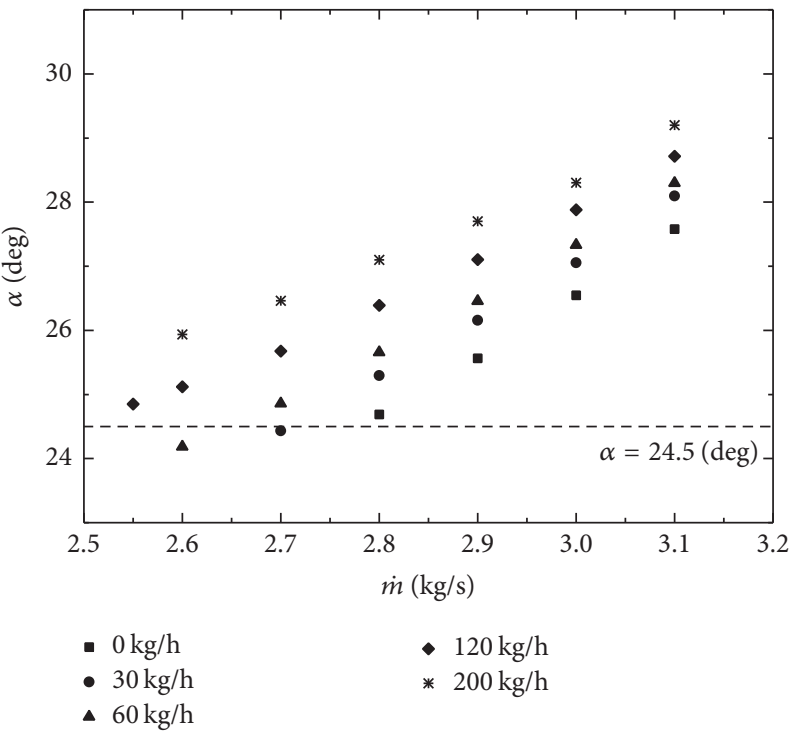

(a) 0 (hub) -0.8 span averaged flow angle

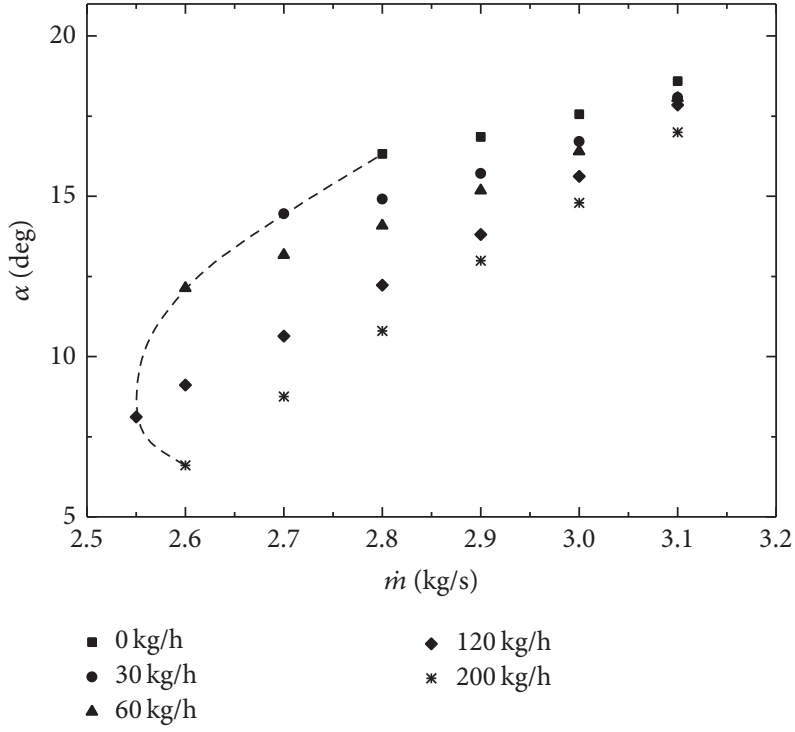

(b) $0.8-1$ (shroud) span averaged flow angle

FIGURE 17: Flow angle at diffuser inlet of different span ranges.

diffuser can be decomposed to 20 small diffuser segments and each of them operates at its own working condition. Results show that the impeller efficiency stays constant at different steam injected flow rates, which means that the injected steam hardly affects the performance of the impeller.

However, the diffuser $\mathrm{Cp}$ near the shroud side shows a large increase with injected steam, while the change of $\mathrm{Cp}$ from hub to $80 \%$ blade height is much smaller. The diffuser $\mathrm{Cp}$ value varies obviously as the steam flow rate increases from $30 \mathrm{~kg} / \mathrm{h}$ to $120 \mathrm{~kg} / \mathrm{h}$.

From the above observed trends, a conjecture can be reached that the vaned diffuser is the dominant component that affects the stage stability.
The trends of diffuser inlet absolute velocity flow angle at different operating conditions and different flow rate steam injection are plotted in Figure 17. In the 0-0.8 span analysis, as the mass flow rate through the compressor decreases from choke to surge, the average absolute flow angle at the diffuser inlet reduces. At the same operating condition, the flow angle increases after steam is injected. It could also increase velocity flow angle at the same operating condition and improve surge margin. Compressor surge occurred when the flow angle reached about 24.5 under all different steam injection flow rate conditions except $200 \mathrm{~kg} / \mathrm{h}$, at which the compressor surge occurred at larger flow rate. Therefore, the surge margin improvement was not in proportion to the steam flow rate. 


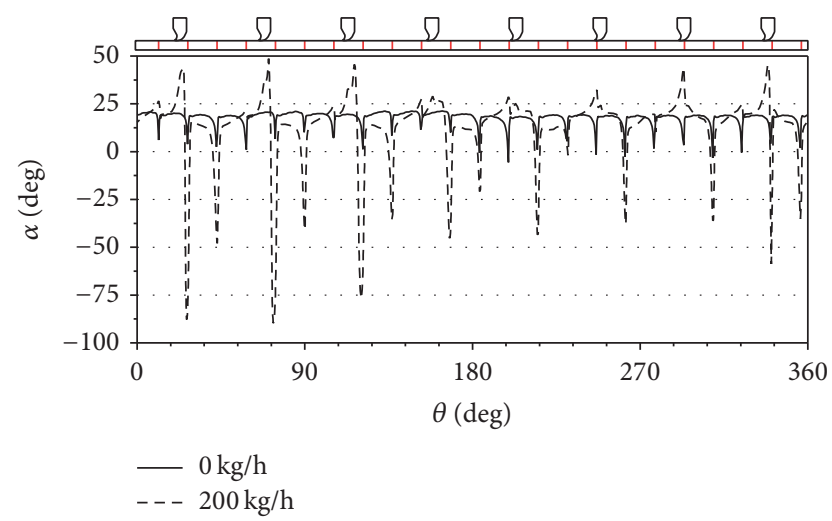

Figure 18: Absolute velocity flow angle at 0.9 span at the diffuser inlet.

In certain cases, the large steam injection rate has a smaller surge margin improvement than small steam injection. This phenomenon could be explained in the $0.8-1$ span analysis. Steam injection could decrease the velocity flow angle at the same operating conditions and deteriorate the flow structure in this area. The velocity flow angle reached the critical value under $200 \mathrm{~kg} / \mathrm{h}$ steam injection condition. Therefore, surge occurred earlier when steam flow rate was $200 \mathrm{~kg} / \mathrm{h}$. This could be attributed to the excessively small velocity flow angle in $0.8-1$ span and will be explained in the following section.

The absolute velocity flow angle at 0.9 span at the diffuser inlet with different steam injection rates was plotted relative to the peripheral direction in Figure 18. Eight steam injectors were uniformly installed upstream of 23 diffuser blades. Their relative positions in the peripheral direction are also shown in the figure. In the current case, the steam is injected in the reverse direction of impeller rotation. Therefore, the direct impact of steam injection was to decrease the circumferential velocity at high span regions and increase the flow angle at the 8 injectors' locations. However, Figure 18 also indicated that flow angle was decreased suddenly as fluid passed through an injector adjacent downstream blade.

If the steam injector is located just between two adjacent diffuser vanes in peripheral direction, flow angle suddenly increased just after the steam injector and flow angle decreased excessively at the neighboring diffuser vane behind this injector. And if the steam injector is located close to a diffuser vane or coincided with a blade in theta direction due to odd number of diffuser vanes, flow angle increased unintelligibly at the steam injection locations, while flow angle decreased slightly at the neighboring diffuser vane behind this injector. In general, as the steam injection flow rate increased from $0 \mathrm{~kg} / \mathrm{h}$ to $200 \mathrm{~kg} / \mathrm{h}$, the flow angle at the steam injector location increased greatly while the flow angle at the neighboring diffuser vane behind this injector decreased excessively.

Detailed flow structures and flow mechanism were studied to explain the feature of the flow angle discussed above. Figure 19 presents the velocity vector field comparison at $90 \%$ span around the diffuser inlet area including two certain steam injectors and their downstream neighboring

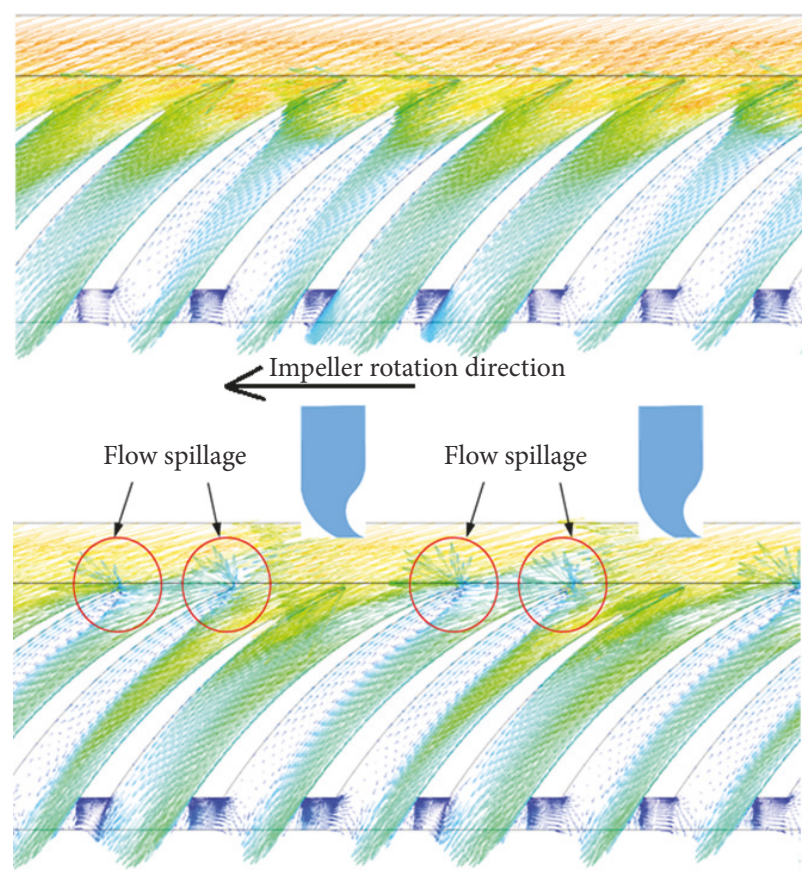

FIGURE 19: Surface streamline at 0.9 span around the diffuser inlet.

diffuser vanes with $0 \mathrm{~kg} / \mathrm{h}$ at numerical surge point and $200 \mathrm{~kg} / \mathrm{h}$ steam injection. As indicated in red circles, with injected steam against the direction of impeller rotation, the circumferential velocity decreased, and thus the diffuser inlet flow angle at high span regions increased. Steam injection causes streamline to turn toward the blade passage, and the flow will spill over adjacent blade leading edge, thus triggering system instability. However, the streamline flowed into the next downstream blade passage instead of the current one affected by the neighboring diffuser vane. This was the main reason that flow angle decreased excessively at the neighboring diffuser vane behind an injector, and separation or blockage in injector positioned diffuser passage may be responsible for the observed behavior. This is quite similar to those found in axial compressor.

To figure out how the steam injection affected the flow angle, the circumferential velocity and the radial velocity versus the normalized span location at the diffuser inlet with a main flow rate of $2.8 \mathrm{~kg} / \mathrm{s}$ are shown in Figure 20, respectively. In general, large injection mass flow generated a stronger influence on the velocity. But the influence was not linear with respect to the span location. The variation of $V_{\theta}$ was limited to the high span space due to the Coanda effect, and a uniform $V_{\theta}$ is obtained for different injection flow rate below 0.5 span, while $V_{r}$ decreased near the shroud side and increased near the hub side. This was because the main flow rate, which is directly associated with $V_{r}$, was set to be a constant value. If the mass through the high span space was reduced, the mass through the low span space must increase to maintain a constant mass flow. The coupled influence by $V_{\theta}$ and $V_{r}$ increased the flow angle in the low span and decreased it in the high span. 


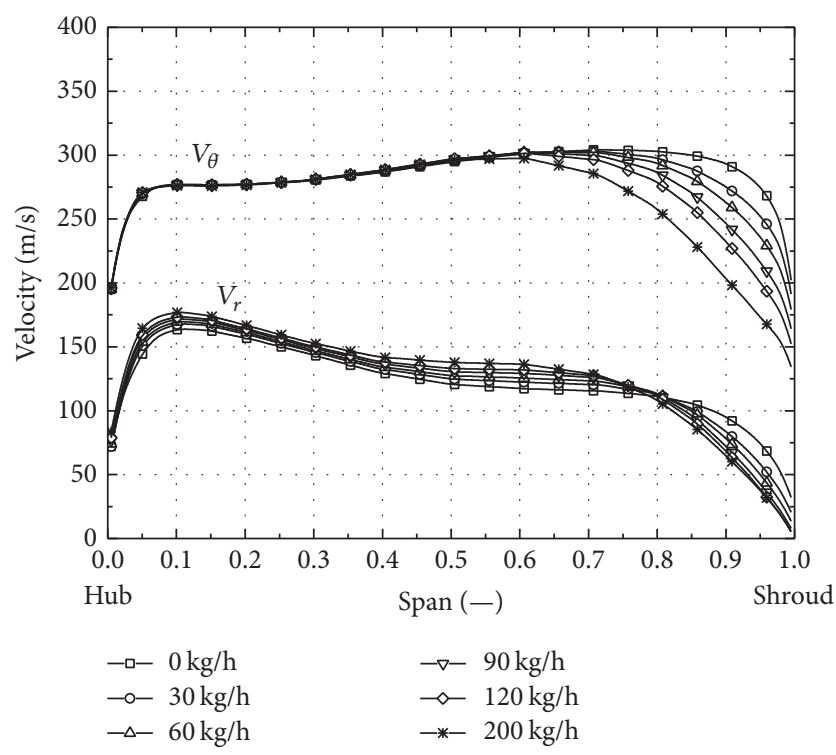

Figure 20: $V_{\theta}$ and $V_{r}$ with different steam injection at the diffuser inlet.

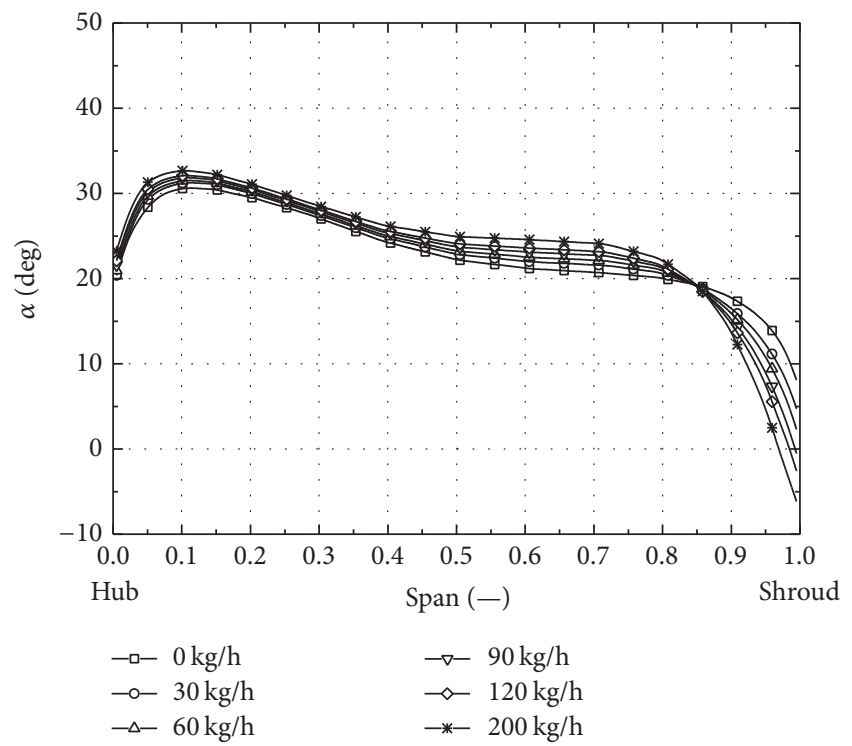

FIGURE 21: Flow angle with different steam injection at the diffuser inlet.

However, this could not explain why there was a cross point of the flow angles versus the normalized span location at the diffuser inlet at different steam injection rate conditions, as illustrated in Figure 21. The authors believe that it should be caused by the Coanda effect which means the radial attached span will remain unchanged regardless of the change in the injected mass flow.

\section{Influences of Thermal Physics Properties}

7.1. Molecular Weight. To study the material influence, three ideal gases were chosen: steam $(M<29), \mathrm{N}_{2}(M \approx 29)$, and $\mathrm{CO}_{2}(M>29)$. To eliminate the influences of other factors
TABLE 3: Boundary conditions of different materials.

\begin{tabular}{lccc}
\hline Gas & $\begin{array}{c}\text { Compressor } \\
\text { mass flow }(\mathrm{kg} / \mathrm{s})\end{array}$ & $\begin{array}{c}\text { Injected gas } \\
\text { static } \\
\text { temperature }(\mathrm{K})\end{array}$ & $\begin{array}{c}\text { Injected gas } \\
\text { mass flow } \\
(\mathrm{kg} / \mathrm{s})\end{array}$ \\
\hline Steam ideal gas & 2.80 & 438 & 0.0333 \\
$\mathrm{~N}_{2}$ ideal gas & 2.80 & 438 & 0.0416 \\
$\mathrm{CO}_{2}$ ideal gas & 2.80 & 438 & 0.0521 \\
\hline
\end{tabular}

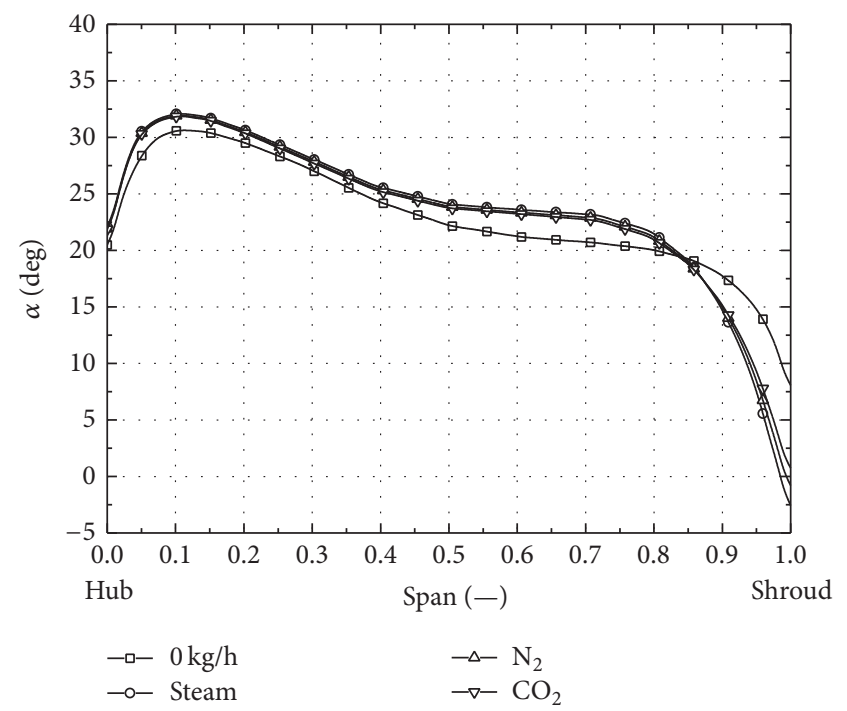

FIGURE 22: Flow angle in span direction.

TABLE 4: Boundary conditions of different temperatures.

\begin{tabular}{lccc}
\hline $\begin{array}{l}\text { Injected gas } \\
\text { static } \\
\text { temperature (K) }\end{array}$ & $\begin{array}{c}\text { Compressor } \\
\text { mass flow }(\mathrm{kg} / \mathrm{s})\end{array}$ & Gas injected & $\begin{array}{c}\text { Injected gas } \\
\text { mass flow }(\mathrm{kg} / \mathrm{s})\end{array}$ \\
\hline 573 & 2.80 & $\mathrm{~N}_{2}$ & 0.0364 \\
438 & 2.80 & $\mathrm{~N}_{2}$ & 0.0416 \\
293 & 2.80 & $\mathrm{~N}_{2}$ & 0.0508 \\
223 & 2.80 & $\mathrm{~N}_{2}$ & 0.0583 \\
173 & 2.80 & $\mathrm{~N}_{2}$ & 0.0662 \\
\hline
\end{tabular}

involved, the authors keep the momentum of injected gas constant. The related injected gas properties are given in Table 3.

Figure 22 compares the flow angle from hub to shroud. Slight discrepancies can be observed. The results show that the diffuser inlet flow angle decreases from hub to shroud. The light gas can reduce $0.87-1$ span flow angle and enhance it at $0-0.87$ span and increase span averaged flow angle.

Figure 23 illustrates the volume fraction from hub to shroud obtained from the meridional surface at the same radius of the injectors. Mass flow in Table 4 and volume fraction in Figure 23 indicate that the larger the mass flow is, the larger the volume fraction injected is.

7.2. Temperature and Heat Transfer. Figure 24 compares the flow angle from hub to shroud. The results show that the 


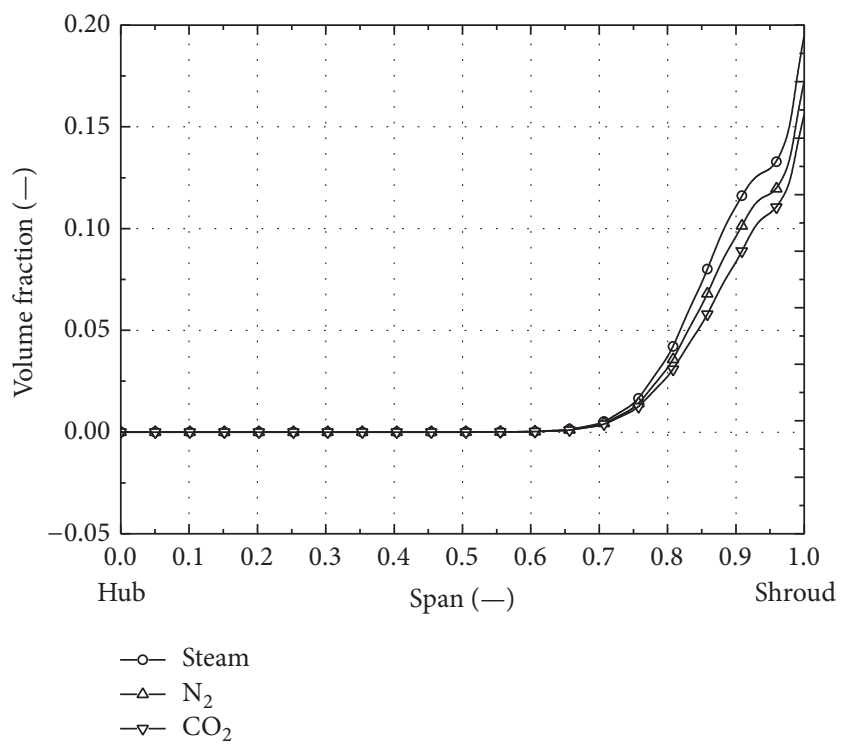

FIGURE 23: Volume fraction obtained from the meridional surface at the same radius of the injectors.

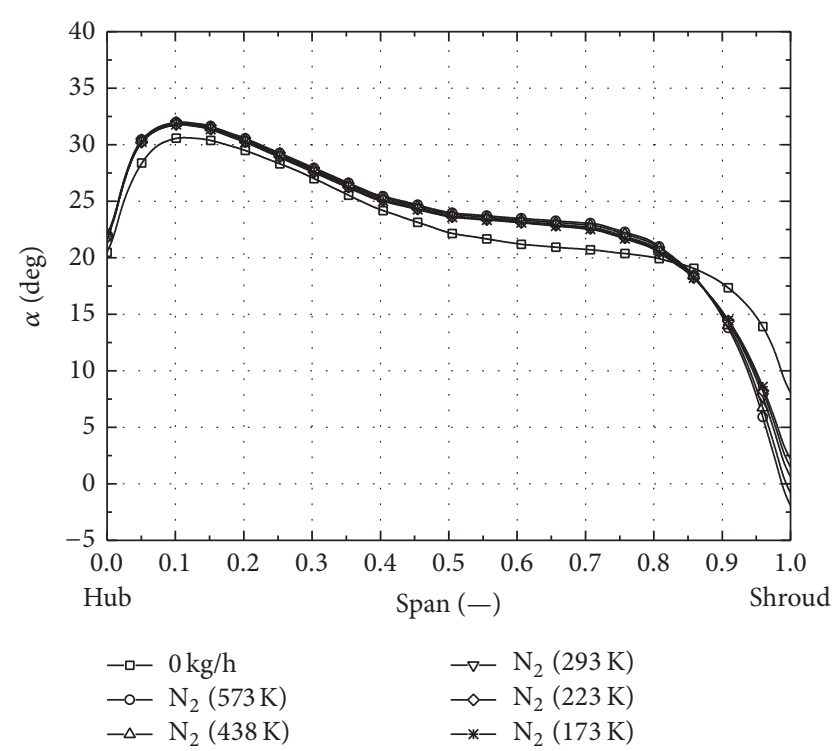

FIgURE 24: Flow angle in span direction of different temperatures.

diffuser inlet flow angle decreases from hub to shroud. The higher gas temperature can reduce $0.87-1$ span flow angle and enhance it at 0-0.87 span and thus increase span averaged flow angle.

Figure 25 depicts the volume fraction from hub to shroud obtained from the meridional surface at the same radius of the injectors. It shows that the larger the mass flow is, the smaller the volume fraction is.

The volume flow as the dominant factor that changes the flow angle can be concluded by the comparisons of mass and volume flow influence above. Therefore, with the same momentum injection, higher temperature or smaller molecular weight gas can both increase the diffuser inlet flow

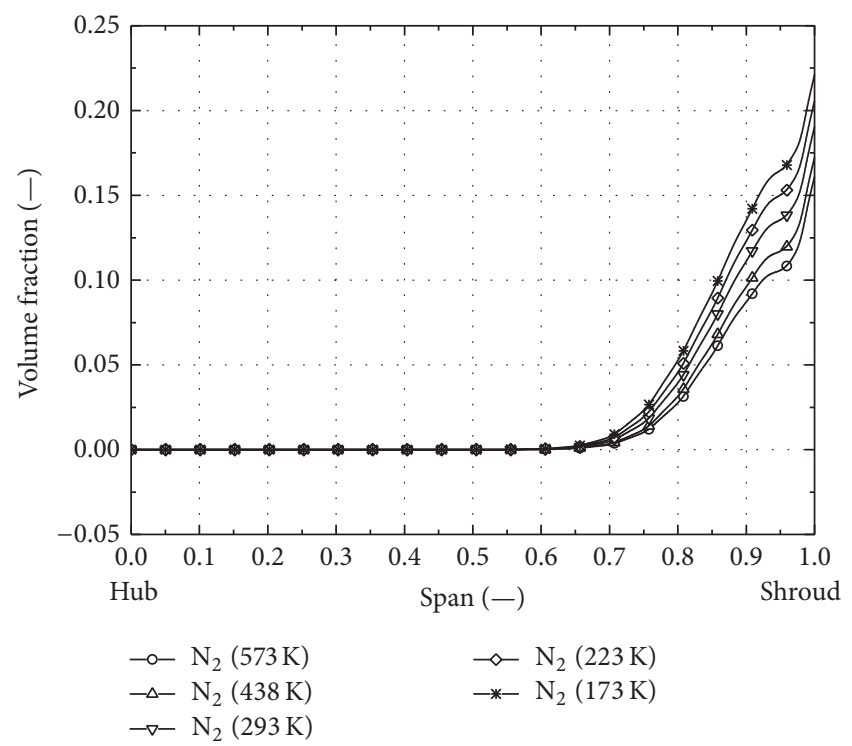

FIGURE 25: Volume fraction obtained from the meridional surface of different temperatures.

angle and extend the compressor stable operation range. For example, if the injected gas temperature is higher than the air temperature, then it will heat up the air, cause it to expand, and thus increase radial velocity near the shroud side.

7.3. Asymmetric and Symmetric Injector, Air Bleeding, and Air Recirculation. As discussed above, the injector position would affect the flow pattern downstream of that injector significantly. In order to figure out the influence on the enhancement, cases of 8 asymmetrically distributed injectors and 23 uniformly distributed injectors were simulated here. $\eta \Delta$ and $\alpha \Delta$ represent the efficiency variation rate under the surge limit and the change rate of the mean flow angle at the inlet of the diffuser vane space compared to those of cases without injection, respectively. The results demonstrate that the change of the injector position does not improve the enhancement compared with the former cases, and a distinct decrease of efficiency was captured for the case of 23 injectors.

At last, the air bleeding and air recirculation were tested, as shown in Figure 26. Air bleeding out from the pipes installed at each vane passage throat was discharged to the environment or reinjected to the diffuser vaneless space. The total air bleeding mass flow was set to be $30 \mathrm{~kg} / \mathrm{h}$. The air recirculation flow was driven by the differential pressure between the vane throat and vaneless space, measured as about $135 \mathrm{~kg} / \mathrm{h}$. But SMI is only about $1 / 3$ of the case of steam injection. It shows that the air bleeding configuration enhances the stability with an increase of efficiency, while the injection configurations decrease it. But it is confused that the air recirculation, which can be regarded as a combination of bleeding out and injection, reduces the surge margin distinctly. A positive influence on the flow angle, which the air recirculation had, always indicates an increase of the surge margin; however, it failed in this case. The reason may be the complex flow in the bleeding tubes that affects the convergence of the simulations. 

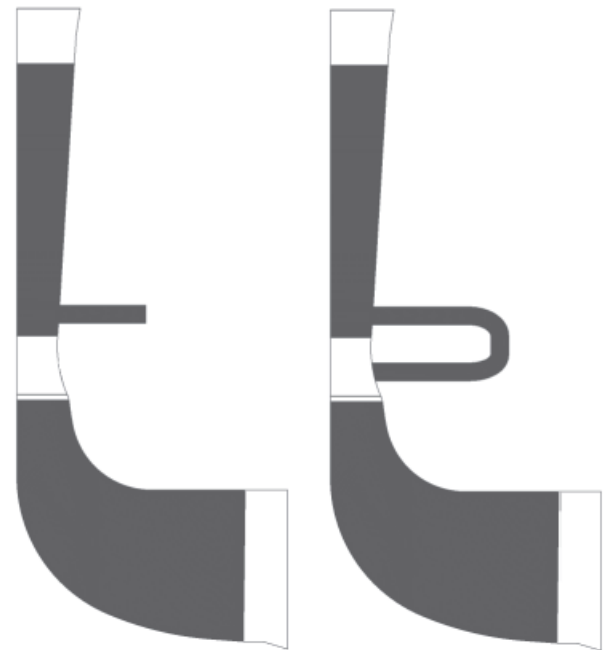

FIgURE 26: Air bleeding and air recirculation configuration.

\section{Conclusions}

A centrifugal compressor with vaned diffuser was analyzed in detail through both experimental and numerical methods. After comparing the steady CFD results and unsteady test data, some conclusions could be made as follows:

(a) Steam injection is shown to be an effective method to improve stage stability. $0.3 \%$ of compressor designed mass flow rate steam can increase the surge margin by over $9.0 \%$ at $\mathrm{Mu}=1.08$. At each speed line, there is an optimum steam flow rate.

(b) Steam injection changes the type of stall precursor from spike to modal waves at $90 \%$ speed line. In addition, it changes the stall cell traveling direction from forward to backward at $80 \%$ speed.

(c) Both efficiency and pressure ration drop with steam injection.

(d) The root cause of the compressor surge is the flow angle at the diffuser inlet, and the surge margin could be improved by decreasing the incidence angle at the diffuser inlet.

(e) At the same momentum injection, higher temperature or lighter gas can increase the diffuser inlet flow angle and extend the compressor stable operation range.

(f) The 8 asymmetrical injectors and the 23 circumferentially symmetrical injectors performed less and equal enhancement compared with the normal configuration, respectively. A distinct decrease of efficiency occurred for the 23-injector case, which demonstrated a more pressure loss. The air bleeding increased the stability and the efficiency. But the air reinjection had a negative effect on the surge margin.

(g) Traditional flow instability theory based on incidence caused flow separation can still be applied for vaned diffuser by viewing its spanwise distribution. (h) Symmetric injector is better than asymmetric case from the point of SMI.

(i) Steam injection is more effective than simple bleeding at throat area or recirculation in SMI but will result in a drop of efficiency.

\section{Nomenclature}

$\begin{array}{ll}p: & \text { Pressure }(\mathrm{kPa}) \\ b: & \text { Axial width }(\mathrm{mm}) \\ r: & \text { Radius }(\mathrm{mm}) \\ f_{s}: & \text { Sampling frequency }(\mathrm{kHz}) \\ Q: & \text { Volumetric flow rate }\left(\mathrm{m}^{3} / \mathrm{s}\right) \\ T: & \text { Temperature }(\mathrm{K}) \\ V: & \text { Absolute velocity }(\mathrm{m} / \mathrm{s}) \\ W: & \text { Relative velocity }(\mathrm{m} / \mathrm{s}) \\ U: & \text { Impeller circumferential velocity }(\mathrm{m} / \mathrm{s}) \\ n: & \text { Impeller rotational speed }(\mathrm{rpm}) \\ N: & \text { Number of blades }(-)\end{array}$

TWE: Traveling wave energy.

\section{Greek Symbols}

$\alpha$ : Absolute flow angle from tangential direction $\left({ }^{\circ}\right)$

$\beta$ : Blade angle from tangential direction $\left(^{\circ}\right)$

$\phi$ : Flow coefficient defined as $Q / \pi r_{2}^{2} u_{2}$

$\psi$ : Pressure rise coefficient defined as $\Delta P /(1 / 2) \rho_{\infty} u_{2}{ }^{2}$

$\rho$ : Density.

\section{Subscripts}

0: Stage inlet

1: Impeller inlet

2: Impeller outlet/vaned diffuser inlet

3: Vaned diffuser outlet

4: Collector outlet

$r$ : Radius direction

$\theta$ : Tangential direction

$\infty$ : Atmospheric condition.

\section{Conflicts of Interest}

The authors declare that they have no conflicts of interest.

\section{Acknowledgments}

This project is supported by the National Natural Science Foundation of China under Grants nos. 51306199 and 51405130. The authors would like to acknowledge the kind comments and discussions on the design of the test facility by Colin Rodgers.

\section{References}

[1] E. Greitzer, "The stability of pumping systems," ASME Journal of Fluids Engineering, vol. 103, no. 11, pp. 193-242, 1981.

[2] Z. S. Spakovszky, "Backward traveling rotating stall waves in centrifugal compressors," Journal of Turbomachinery, vol. 126, no. 1, pp. 1-12, 2004. 
[3] M. Schleer, S. J. Song, and R. S. Abhari, "Clearance effects on the onset of instability in a centrifugal compressor," Journal of Turbomachinery, vol. 130, no. 3, Article ID 031002, 11 pages, 2008.

[4] D. Hagelstein, K. Hillewaert, R. A. Van Den Braembussche, A. Engeda, R. Keiper, and M. Rautenberg, "Experimental and numerical investigation of the flow in a centrifugal compressor volute," Journal of Turbomachinery, vol. 122, no. 1, pp. 22-31, 2000.

[5] Z. S. Spakovszky and C. H. Roduner, "Spike and modal stall inception in an advanced turbocharger centrifugal compressor," Journal of Turbomachinery, vol. 131, no. 3, Article ID 031012, 2009.

[6] H. Tsurusaki and T. Kinoshita, "Flow control of rotating stall in a radial vaneless diffuser," Journal of Fluids Engineering, Transactions of the ASME, vol. 123, no. 2, pp. 281-286, 2001.

[7] W. Huang, S. Geng, J. Zhu, and H. Zhang, "Numerical simulation of rotating stall in a centrifugal compressor with vaned diffuser," Journal of Thermal Science, vol. 16, no. 2, pp. 115-120, 2007.

[8] G. J. Skoch, "Experimental investigation of diffuser hub injection to improve centrifugal compressor stability," Journal of Turbomachinery, vol. 127, no. 1, pp. 107-117, 2005.

[9] T. Hirano, T. Uchida, and H. Tsujita, "Control of surge in centrifugal compressor by using a nozzle injection system: universality in optimal position of injection nozzle," International Journal of Rotating Machinery, vol. 2012, Article ID 259293, 8 pages, 2012.

[10] C. Gao, C. Gu, T. Wang, and B. Yang, "Analysis of geometries' effects on rotating stall in vaneless diffuser with wavelet neural networks," International Journal of Rotating Machinery, vol. 2007, Article ID 76476, 2007.

[11] K. B. Abidogun, "Effects of vaneless diffuser geometries on rotating stall," Journal of Propulsion and Power, vol. 22, no. 3, pp. 542-549, 2006.

[12] X. Sun, D. Sun, and W. Yu, "A model to predict stall inception of transonic axial flow fan/compressors," Chinese Journal of Aeronautics, vol. 24, no. 6, pp. 687-700, 2011.

[13] F. B. Fisher, "Application of map width enhancement devices to turbocharger compressor stages," SAE255 Paper No. 8809794. Power boost: light, medium and heavy duty engines. SP-780, 1989.

[14] M. Werner, R. Baar, P. Haluska et al., "Bidirectional flow measurement based on the differential pressure method for surge analysis on a small centrifugal compressor", proceedings of the institute of mechanical engineers, part A," Journal of Power and Energy, Turbocharger and Turbocharging Special Issue, 2016.

[15] A. Stein, S. Niazi, and L. N. Sankar, "Computational analysis of stall and separation control in centrifugal compressors," Journal of Propulsion and Power, vol. 16, no. 1, pp. 65-71, 2000.

[16] C. Gao, C. Gu, T. Wang, and B. Yang, "Passive control of rotating stall in vaneless diffuser with radial grooves: detailed numerical study," in Proceedings iof the 2009 ASME Turbo Expo, pp. 12251232, Orlando, Fla, USA, June 2009.

[17] R. Taghavi-Zenouz, E. Solki, and H. Afshari, "Stall margin improvement of a centrifugal compressor utilizing various stepped tip gap configurations," Proceedings of the Institution of Mechanical Engineers, Part A: Journal of Power and Energy, vol. 228, no. 7, pp. 772-781, 2014.

[18] G. W. Felsing and Moller P. S., "Coanda flow over circular cylinder with injection normal to surface," AIAA Journal, vol. 7, no. 5, pp. 842-846, 1969.
[19] R. L. Davis and J. Yao, "Computational approach for predicting stall inception in multistage axial compressors," Journal of Propulsion and Power, vol. 23, no. 2, pp. 257-265, 2007.

[20] M. Tryfonidis, O. Etchevers, J. D. Paduano, A. H. Epstein, and G. J. Hendricks, "Pre-stall behavior of several high-speed compressors," Journal of Turbomachinery, vol. 117, no. 1, pp. 6280, 1995.

[21] C. S. Tan, I. Day, S. Morris, and A. Wadia, "Spike-type compressor stall inception, detection, and control," Annual Review of Fluid Mechanics, vol. 42, pp. 275-300, 2010.

[22] Y.-S. Yoon and S. J. Song, "Analysis and measurement of the impact of diffuser width on rotating stall in centrifugal compressors," Journal of Mechanical Science and Technology, vol. 28, no. 3, pp. 895-905, 2014.

[23] Y. Bousquet, X. Carbonneau, G. Dufour, N. Binder, and I. Trebinjac, "Analysis of the unsteady flow field in a centrifugal compressor from peak efficiency to near stall with full-annulus simulations," International Journal of Rotating Machinery, vol. 2014, Article ID 729629, 11 pages, 2014.

[24] C. Gao, W. G. Huang, H. W. Zhang, Y. L. Yao, and J. C. Duan, "Surge characteristics and range extension with steam injection in a centrifugal compressor with vaned diffuser," in Proceedings of the ASME, 2013, International Mechanical Engineering Congress \& Exposition (IMECE '13), San Diego, Calif, USA, November 2013. 


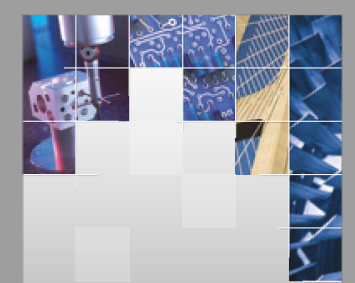

\section{Enfincering}
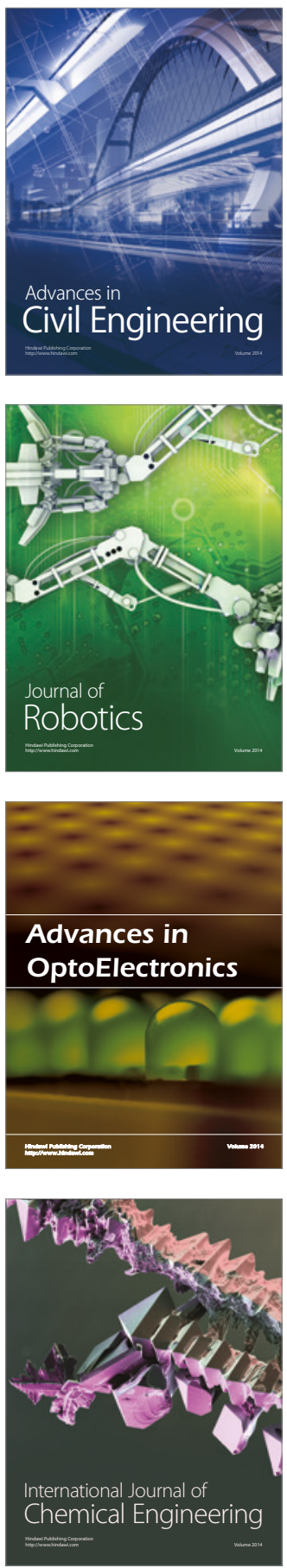

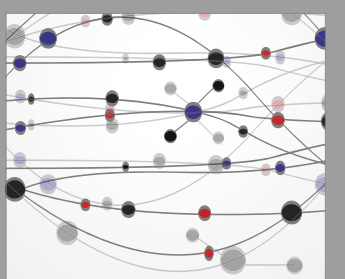

The Scientific World Journal

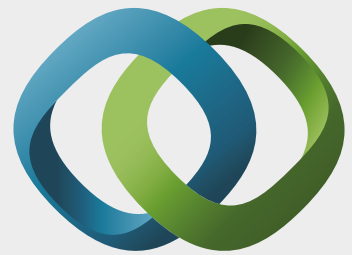

\section{Hindawi}

Submit your manuscripts at

https://www.hindawi.com
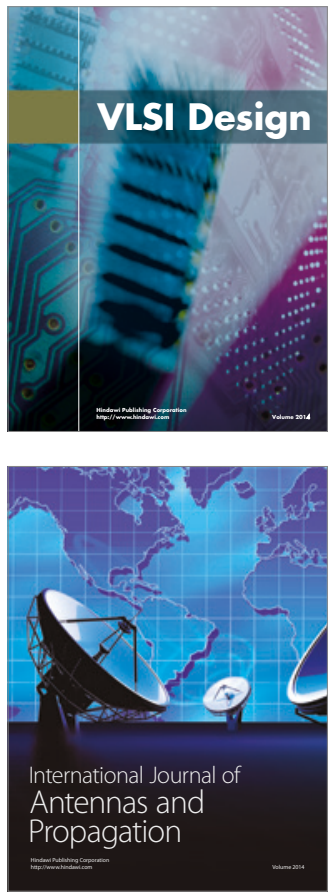

\section{Rotating}

Machinery
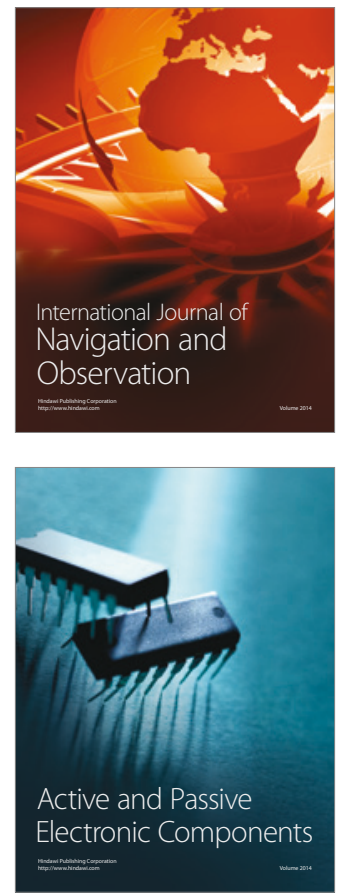
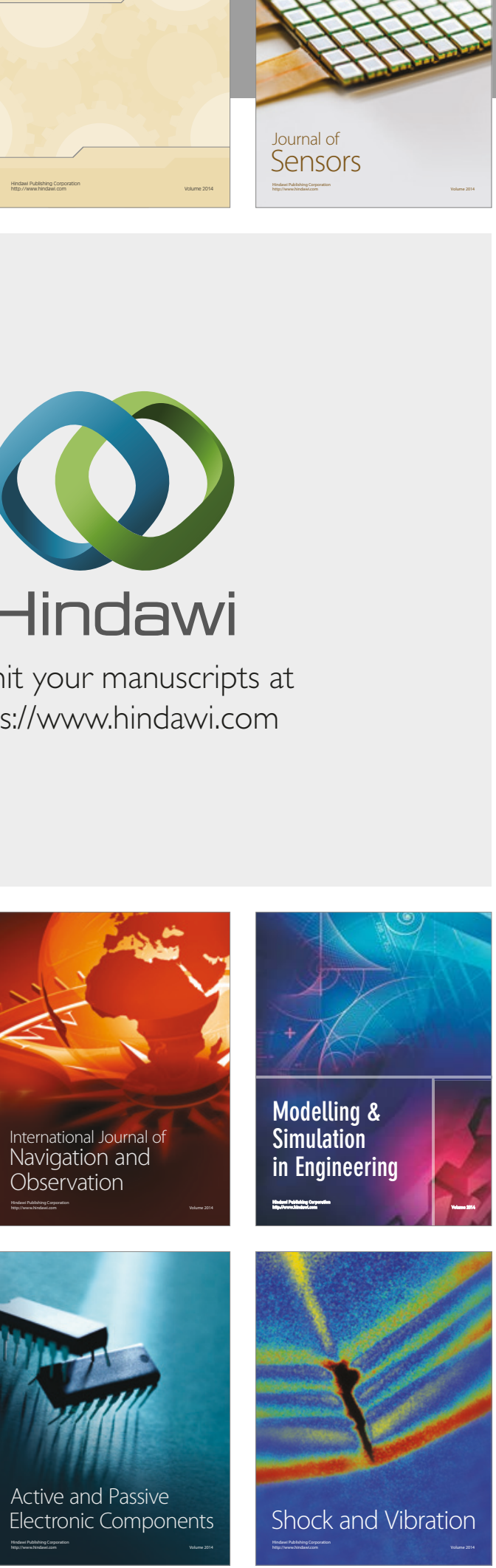
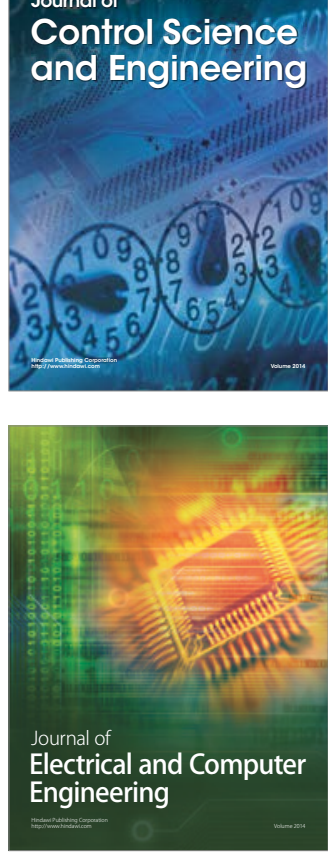

Distributed

Journal of

Control Science

and Engineering
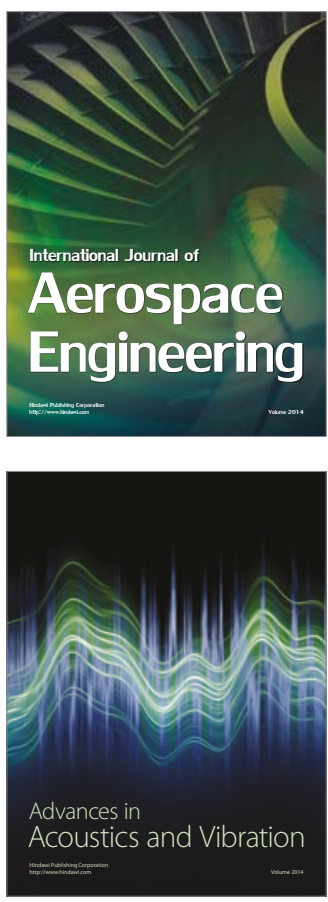

Sensor Networks 